\title{
SAVANNAH RIVER LABORATORY MONTHLY REPORT
}

\author{
${ }^{238} \mathrm{Pu}$ Fuel Form Processes
}




\section{NOTICE}

This report was prepared as an account of work sponsored by the United State Government. Neither the United States nor the United States Energy Research and Development Administration, nor any of their contractors, subcontractors, or their employees, makes any warranty, express or implied, or assumes any legal liability or responsibility for the accuracy, completeness or usefulness of any information, apparatus, product or process disclosed, or represents that its use would not infringe privately owned rights. 


\title{
SAVANNAH RIVER LABORATORY MONTHLY REPORTT
}

\author{
238pu Fuel Form Processes
}

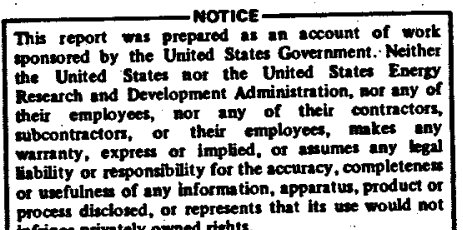

of unefulness of any information, apparalus, product or

profringe privitely owned rithts.

\section{August 1975}

This document is

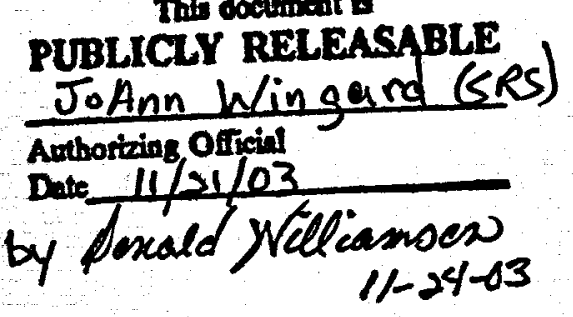

E. I. du Pont de Nemours \& Co.

Savannah River Laboratory

Aiken, S. C. 29801

PREPARED FOR THE U. 8. ENERGY RESEARCH AND DEVELOPMENT ADMINISTRATION UNDER CONTRACT AT(07-2)-1 


\section{DISCLAIMER}

This report was prepared as an account of work sponsored by an agency of the United States Government. Neither the United States Government nor any agency thereof, nor any of their employees, makes any warranty, express or implied, or assumes any legal liability or responsibility for the accuracy, completeness, or usefulness of any information, apparatus, product, or process disclosed, or represents that its use would not infringe privately owned rights. Reference berein to any specific commercial product, process, or service by trade name, trademark, manufacturer, or otherwise does not necessarily constitute or imply its endorsement, recommendation, or favoring by the United States Government or any agency thereof. The views and opinions of authors expressed herein do not necessarily state or reflect those of the United States Government or any agency thereof. 


\section{DISCLAIMER}

Portions of this document may be illegible in electronic image products. Images are produced from the best available original document. 


\section{SUMMARY}

concluded:

In studies to characterize ${ }^{238} \mathrm{PuO}_{2}$, the following were

- Particle size was determined to be the most important characteristic affecting the variation in fabricability of ${ }^{238} \mathrm{PuO}_{2}$.

- Problem feed consists of smaller particles ( 2 to $4 \mu \mathrm{m}$ ) than older, acceptable feed (4 to $6 \mu \mathrm{m})$. The particle size of new feed has varied from 3 to $10 \mu \mathrm{m}$ primarily as a result of varying precipitation temperature. ( $p$ 9)

- Equations have been developed from statistically designed precipitation experiments that relate precipitation temperature, nitric acid concentration, and plutonium concentration to particle size.

- Characteristics of acceptable feed have been defined: a particle size mode of 4.5 to $6.0 \mu \mathrm{m}$, with an agglomeration index of 20 to $50 \mathrm{wt} \%$, and 0 to $15 \mathrm{wt} \%$ of fines ( $<2 \mu \mathrm{m}$ particles).

- Precipitation temperature is the most important variable affecting particle size.

- Desired particle characteristics can be achieved by precipitating at $35 \pm 5^{\circ} \mathrm{C}, 1.2 \pm 0.1 \mathrm{M}$ nitric acid, and 4 to $7 \mathrm{~g} / 1$ plutonium in the feed solution.

No deleterious effects from ultrasonic decontamination were observed on either fuel form simulants or the iridium containment shells.

Helium release studies show that shards can be stored for over a year without producing microstructural damage in hotpressed products.

Temperature gradients of only $50^{\circ} \mathrm{C}$ during shard seasoning can affect product quality. 
Presintering of cold-pressed pellets before breakup produces shards for the Milliwatt Radioisotopic Thermoelectric Generator Program (Milliwatt) with a minimum of fines. Fines content of these shards compares favorably with the fines associated with the Mound Laboratory hydroxide shards.

${ }^{23}{ }^{8} \mathrm{PuO}_{2}$ scrap recovery has been terminated due to insufficient funds. 


\section{CONTENTS}

Page

Introduction . . . . . . . . . . . . . . . 7

Technical Assistance for ${ }^{238} \mathrm{PuO}_{2}$. . . . . . . . . 8

Characterization of ${ }^{238} \mathrm{PuO}_{2}$. . . . . . . . . 8

Analysis of Particle Characteristics . . . . . . 8

Analysis of Precipitation Variables . . . . . . . 12

Equations for Determining Particle Characteristics . . 14

Application to SRP Production . . . . . . . . . 20

Control of Production Processes . . . . . . . . 21

Program . . . . . . . . . . . . • . . 25

Multi-Hundred Watt Process Demonstration . . . . . . 26

U1trasonic Cleaning of Iridium-Clad Simulant Spheres . . 26

Effect of Shard Aging on Microstructure of Hot-

Pressed PPO Pellets . . . . . . . . . . . 27

Effect of Temperature on Shard Morphology . . . . . 27

Milliwatt Process Development . . . . . . . . 31

Shard Fabrication Process . . . . . . . . . . . 31

Development of Shard Process . . . . . . . . . 31

Fines Content . . . . . . . . . . . . 36

Packing Density . . . . . . . . . . . . . .

Recommended Process . . . . . . . . . . . 38

Program . . . . . . . . . . . . . 40

Equipment and Facilities . . . . . . . . . . 41

Alpha Materials Facility . . . . . . . . . . 41

Scrap Recovery . . . . . . . . . . . . . . 41

References . . . . . . . . . . . . • 42 


\section{INTRODUCTIION}

This report is one of a series to summarize progress in the Savannah River ${ }^{2{ }^{3} \mathrm{Pu}}$ Fuel Form Program; this program is supported by the ERDA Division of Space Nuclear Systems (DSNS) and the ERDA Division of Military Applications (DMA).

Goals of the Savannah River Laboratory (SRL) program for SNS are: to provide technical support for the transfer of SNS and DMA ${ }^{2{ }^{3} \mathrm{Pu}}$ fuel form fabrication operations from Mound Laboratory to new facilities being built at the Savannah River Plant (SRP), to provide the technical basis for ${ }^{238} \mathrm{Pu}$ scrap recovery at SRP, and to assist in sustaining plant operations. This part of the program includes:

Demonstration of processes and techniques, currently in use at Los Alamos Scientific Laboratory (LASL) and Mound, for production at SRP, thereby providing design information and the data upon which technical standards and operating procedures will be based.

Technical Support to assist plant startup and to ensure continuation of safe and efficient production of high quality heat source fuel.

Technical Assistance after startup to accommodate changes in product and product specifications, to assist user agencies in improving product performance, to assist SRP in making process improvements that increase efficiency and product reliability, and to adapt plant facilities for new products. 


\section{TECHNICAL ASSISTANCE FOR ${ }^{238} \mathrm{PuO}_{2}$ PRODUCTION}

\section{CHARACTERIZATION OF ${ }^{23}{ }^{8} \mathrm{PuO}_{2}$}

The variation in fabricability of ${ }^{238} \mathrm{PuO}_{2}$ was determined to be caused primarily by a variation in particle size. Individual ${ }^{23} \mathrm{PuO}_{2}$ particles in problem feed are smaller ( 2 to $4 \mu \mathrm{m}$ ) than found in older feed (4 to $6 \mu \mathrm{m})$. The decrease in size for problem ${ }^{238} \mathrm{PuO}_{2}$ was caused by decreased solubility of plutonium during precipitation as a result of lower precipitation temperatures $\left(22\right.$ to $\left.30^{\circ} \mathrm{C}\right)$ and lower nitric acid concentrations in the feed solution $(0.4$ to $0.9 \mathrm{M})$. Precipitation studies have shown that the desired size of 4.5 to $6 \mu \mathrm{m}$ can be obtained at the SRP by precipitating at $35 \pm 5^{\circ} \mathrm{C}$, with $1.2 \pm 0.1 \mathrm{M}$ nitric acid and 4 to 7 $\mathrm{g} / 1$ plutonium in the feed solution. Equations have been developed relating particle size, agglomeration, and fines content as functions of precipitation temperature, acid concentration, and plutonium concentration. ${ }^{238} \mathrm{PuO}_{2}$ produced in 1975 has inconsistent properties because the precipitation temperature varied.

\section{Analysis of Particle Characteristics}

Sufficient data on particle size characteristics and tap densities of SRP feed and on fabrication response at LASL are now available to obtain a definition of acceptable and problem feed. Varying fabrication response has been caused by a variation in particle size between modes of 2 and $6 \mu \mathrm{m}$. The mode is taken as the particle size at the maximum in the histogram of mass particle size distribution for the smaller particle component of the bimodal distribution, i.e., for the distribution representing individual particles as opposed to agglomerates (see Figure 5, June report). The mode does not usually differ from the median very much and has two advantages over the median as a fundamental characteristic of the individual particles. First, the median is computed for the entire bimodal distribution and is strongly affected by the amount and distribution of agglomerates. Second, as shown in the June report, agglomerates are comprised of particles which have the same mode as for the individual particles.

Table 1 lists the precipitation conditions and particle size characteristics for all of the SRP runs examined at the SRL to date. The data are separated into three categories by production date: old feed with generally acceptable fabricability, problem feed with generally unacceptable fabricability, and new production in 1975 during which efforts were being made at SRP to obtain 
better control of the production equipment and processing parameters.

Based on the mode sizes in Table 1 and the more exterisive LASL data on particle size of SRP feed lots (January 1975 report), the particle size of acceptable feed is larger than that for problem feed. As summarized in Table 2, acceptable feed has a mode between 4 and $6 \mu \mathrm{m}$, and problem feed has a mode between 2 and $4 \mu \mathrm{m}$. On this basis, not every run of old feed appears to be acceptable, nor is every run of problem feed unacceptable. The mode varied appreciably because of variations in temperature, acid concentration, and plutonium concentration within allowable process limits. The general decrease in acid concentration during the problem period caused the modes to be generally too small.

Table 2 also shows the characteristic agglomeration index and fines content of acceptable and problem feed based on the data in Table 1. In general, acceptable feed has an agglomeration index between 30 and $50 \mathrm{wt} \%$; however, this parameter strongly overlaps the range observed for problem feed. The range of fines content, $i . e .$, wt $\%$ of particles measuring less than $2 \mu \mathrm{m}$, is smaller for acceptable feed than for problem feed, reflecting the generally larger size of all the particles in acceptable feed.

The assignment of particle sizes which are characteristic of acceptable and problem feed is based on the fabricability of various feed lots at LASL. LASL fabrication was performed on different batches of many of the same lots listed in Table 1. Runs from any single lot of plutonium feed (same plutonium and nitric acid concentrations for all runs) have a higher probability of having similar particle size characteristics, and data from the same lots should provide support for the definition of acceptable and problem feed. Table 3 compares fabricability at LASL to the mode determined at SRL on runs from the same 10t. Feed with modes of 4.5 to $5.8 \mu \mathrm{m}$ were generally acceptable, feed with modes smaller than $3 \mu \mathrm{m}$ were unacceptable, and feed with modes much larger than $6 \mu \mathrm{m}$ gave intermediate results. LASL, SRP, and SRL have implemented a program of sample exchange and closer monitoring to compare fabrication response, precipitation parameters, and particle characteristics more definitively. 
TABLE 1 .

Particle SIze Characteristics and Calculated Precipltation Temperatures for SRP ${ }^{2}{ }^{2} \mathrm{PuO}_{2}$

$$
\text { Nitrio }
$$

Feed

Lot no. Aoid

$\begin{array}{ll}\text { HL } 178 & (0.6) \\ \text { HL } 180 & 1.57 \\ \text { HL } 180 & 1.57 \\ \text { HL } 187 & 1.15 \\ \text { HL } 188 & 1.01 \\ \text { HL } 189 & 1.30 \\ \text { HL } 237 & 0.68 \\ \text { HL } 239 & -1.12 \\ \text { HL } 243 & 1.12 \\ \text { HL } 243 & 1.12 \\ \text { HL } 243 & 1.12 \\ \text { HL } 243 & 1.12 \\ \text { HL } 254 & 0.89\end{array}$

Problem

\begin{tabular}{ll} 
HL 265 & 0.57 \\
HL 265 & 0.57 \\
HL 265 & 0.57 \\
HL 266 & 0.85 \\
\hline
\end{tabular}
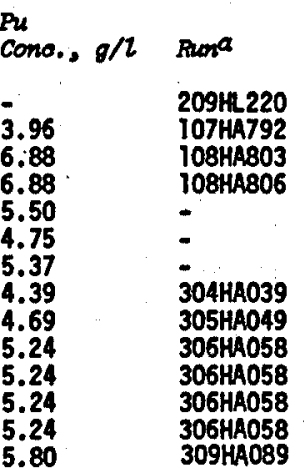

No.

3.96
6.88

6.88

5.50
4.75

5.37

4.39

4.69
5.24

5.24

5.24
5.24

5.80

$\begin{array}{ll}5.80 & 401 \text { HA122 } \\ 5.80 & 401 \text { HA122 }\end{array}$

5.80

5.80

5.96

$401 \mathrm{HA122}$

401 HA1 30
405 HA212

405HA212

\section{HA272}

502HA275A

$502 H A 2758 / C$

504HA296A

04HA296B

504HA296C

504 HA 35

5054312

5064 A321

(5654331

506HA336

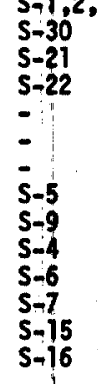

-

$\bar{s}-5$

$S-15$
$S=16$

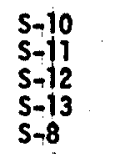

$311: 1.17$

L $314 \cdot 1.15$

$\begin{array}{lll}\text { HLL } & 315 & 1.13 \\ \text { HL } & 316 & 1.25\end{array}$

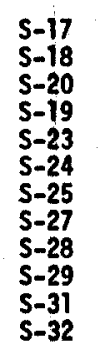

Pptns. SRE

\section{several $5,1,2,3$}

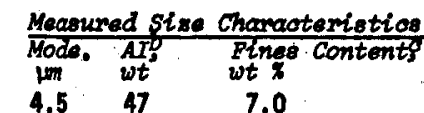

Caloulated

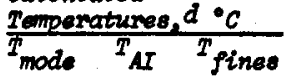

$48 \quad \overline{12} \quad \overline{46}$

$\begin{array}{lll}33 & 25 & 46 \\ 32 & 22 & 40\end{array}$

$(26)^{e} \quad 11 \quad 36$

$\begin{array}{lll}24 & 16 & 31 \\ 22 & 19 & 41 \\ 32 & 35 & 16\end{array}$

29 $28 \quad$

$\begin{array}{lll}290 & 28 & 43\end{array}$

$\begin{array}{lll}28 & 32 & 35 \\ 34 & 30 & 39\end{array}$

$\begin{array}{lll}3.8 & 28 & 18.0 \\ 4 & 12.3\end{array}$

$\begin{array}{llr}4.7 & 30 & 9.0 \\ 3 \text { to } 9 & 52 & 16.0\end{array}$

2.5 to $3.0 \quad 15 \quad 32.2$

$\begin{array}{lll}2.0 & 40 & 41.7 \\ 3.5 & 20 & 20.0 \\ 2.8 & 28 & 23.0\end{array}$

$\begin{array}{lll}5.4 & 11 & 23.0\end{array}$

$\begin{array}{rcr}9.2 & (17)^{6} & 1.2 \\ 7.9 & 0 & 1.3 \\ 10.0 & 13 & 0.7 \\ 6.2 & 8 & 1.9 \\ 5.8 & 40 & 2.9 \\ 5.4 & 35 & 5.8 \\ 5.4 & 40 & 5.7 \\ 4.5 & 23 & 9.0 \\ 4.7 & 40 & 4.3 \\ 3.0 & 22 & 20.7 \\ 3.8 & 32 & 10.0 \\ 3.4 & 23 & 16.6\end{array}$

a. xxHA--- signifies run date; e.g., 502HA--- was precipitated in February of 1975

b. AI = agglomeration index, wt $\%$.

a. Fines content is the wt $\%$ of particles of less than 2 um

d. See text for discussion.

e. Numbers in parentheses are estimated values. 
TABLE 2

Characteristics of SRP $23{ }^{6} \mathrm{PuO}_{2}$ - Summary

\begin{tabular}{|c|c|c|c|c|c|}
\hline \multirow[b]{2}{*}{ Properties } & \multicolumn{5}{|l|}{ Ranges } \\
\hline & Acoeptable & Problem & $\frac{\text { New (1975) }}{\text { February }}$ & $\begin{array}{l}\text { Apxil-May } \\
\text { Aoceptable } \\
\text { Fabrioability }\end{array}$ & $\begin{array}{l}\text { June } \\
\text { Unevaluated } \\
\text { Fabrioability }\end{array}$ \\
\hline Mode of Particle Size, $\mu \mathrm{m}$ & $4.5-6$ & $2-4$ & $6-10$ & $4.5-6$ & $3-4$ \\
\hline Agglomeration Index, wt $x$ & $20-50$ & $15-40$ & $0-15$ & $25-40$ & $20-30$ \\
\hline Fines Content, wt $\%$ & $5-10$ & $20-40$ & $0-2$ & $3-9$ & $10-20$ \\
\hline Final Tap Density, g/cc & $1.9-2.3$ & $2.3-2.8$ & $1.6-2.0$ & $1.9-2.2$ & $2.0-2.4$ \\
\hline
\end{tabular}

Precipitation Conditions

\begin{tabular}{|c|c|c|c|c|c|}
\hline Nitric Acid Conc., M & $0.8-1.6$ & $0.4-0.9$ & $1.1-1.3$ & $1.1-1.3$ & $1.1-1.3$ \\
\hline Temperature, ${ }^{\circ} \mathrm{C}$ & $30-40^{a}$ & $22-30^{a}$ & $40-60^{a}$ & $35-40^{a}$ & $22-28$ \\
\hline Total Pu Conc., $g / 1$ & $4-7$ & $4-7$ & $4-7$ & $4-7$ & $4-7$ \\
\hline
\end{tabular}

a. Calculated; see text for discussion.

TABLE 3

Fabrication Rating from LASL

\begin{tabular}{|c|c|c|c|}
\hline $\begin{array}{l}\text { Feed } \\
\text { Type }\end{array}$ & $\begin{array}{l}\text { Lot } \\
\text { No. }\end{array}$ & $\begin{array}{l}\text { Fabrication } \\
\text { Response }\end{array}$ & $\begin{array}{l}\text { SRP Measurement of } \\
\text { Mode for Sane Lot, } \mathrm{um}\end{array}$ \\
\hline old & HL 178 & acceptable & 4.6 \\
\hline Problem & HL 266 & unacceptable & 2.8 \\
\hline New & HL 301; HA 272 & Intermediate & 10 \\
\hline New & HL 305; HA 289 & acceptable & \\
\hline New & $\begin{array}{l}\text { HL 310; HA } 300 \\
\text { HL 310; HA } 302\end{array}$ & $\begin{array}{l}\text { unacceptablea } \\
\text { close to acceptable }\end{array}$ & $\begin{array}{l}4.5-5.8 \text { for lots } \\
\mathrm{HL} 309, \mathrm{HL} 311 \text {, and } \\
\mathrm{HL} 312\end{array}$ \\
\hline
\end{tabular}

a. Temperature was known to vary widely during production of Lots HL 310 and HA 300. 


\section{Analysis of Precipitation Variables}

Screening experiments reported in the February to June 1975 reports identified three variables in the precipitation of plutonium oxalate to be primary factors controlling particle size and morphology: precipitation temperature, acid concentration, and plutonium concentration. A two-level factorial analysis was completed to assess the relative significance of these three factors and their interactions. Although not strictly obtainable from a two-level factorial design, preliminary equations could be generated from these data. These equations appear sufficiently precise to enable the control of particle size, agglomeration, and fines content of SRP-produced ${ }^{23}{ }^{8} \mathrm{PuO}_{2}$.

. Eight one-gram batches of ${ }^{238} \mathrm{Pu}$ were precipitated in the laboratory under SRP precipitation conditions at two widely different levels for each of the three variables (factors). After calcining at $735^{\circ} \mathrm{C}$ for $2 \mathrm{hr}$, the ${ }^{238} \mathrm{PuO}_{2}$ was analyzed for particle size distribution with a Coulter Counter and by scanning electron microscopy (SEM).

The range of variables and the responses for the eight precipitations in the analysis and for a ninth precipitation near the center of the experiment space are shown in Figure 1 . The four response values shown represent median particle size, agglomeration index, mode particle size, and fines content, respectively.

The SRL experiments (Figure 1) covered a broader range than SRP production conditions to emphasize the effects of the three variables. Nitric acid concentrations in the plutonium feed solution were set at 0.7 and $1.8 \mathrm{M}(1.1$ to $1.3 \mathrm{M}$ is used at SRP in 1975). Plutonium concentrations in the feed were set at 2.0 and $8.0 \mathrm{~g} / 1$ (4 to $7 \mathrm{~g} / 1$ is used at SRP). The temperatures in the precipitator were set at $22^{\circ} \mathrm{C}$ and $45^{\circ} \mathrm{C}$ (SRP temperature is variable but intended to be between 22 and $35^{\circ} \mathrm{C}$ ). The feed solution was preheated to $33^{\circ} \mathrm{C}$ before addition to the oxalic acid to simulate the temperature of $4 \mathrm{~g} / 1$ feed at SRP. The temperature during precipitation was held constant within $1^{\circ} \mathrm{C}$ at $22^{\circ} \mathrm{C}, 45^{\circ} \mathrm{C}$, or $30^{\circ} \mathrm{C}$. An experiment at $30^{\circ} \mathrm{C}, 4.0 \mathrm{~g} \mathrm{Pu} / 1$, and $1.2 \mathrm{M}$ acid was performed to simulate SRP centerline conditions and to provide a measure of factor effects through the center of the experimental space.

The responses shown in Figure 1 indicate sizeable changes in all four particle size characteristics with all three variables. Mode size increases, and both agglomeration and fines content decrease with increasing temperature, increasing acid concentration, and decreasing plutonium concentration. This 
behavior is consistent with the increasing solubility of plutonium oxalate in the same way. For example, surfaces of constant mode are nearly nomal to the [111] axis of the figure, i.e., to the diagonal from Point $C$ to Point $E$, representing the directions of greatest solubility change (Figure 1). The mode size varies from $1.7 \mu \mathrm{m}$ to $12 \mu \mathrm{m}$, agglomeration index from $65 \mathrm{wt} \%$ to $1 \mathrm{wt} \%$, and fines content from $28 \mathrm{wt} \%$ to $0.8 \mathrm{wt} \%$ along this axis.

- Experimental Points

Volues by each point represent particle charocteristics of calcined powder, as follows: Medion Particle Size, $\mu \mathrm{m}$ Agglomeration Index, wt \% Mode of Parficle Size, $\mathrm{mm}$ Fines Content, wt \%
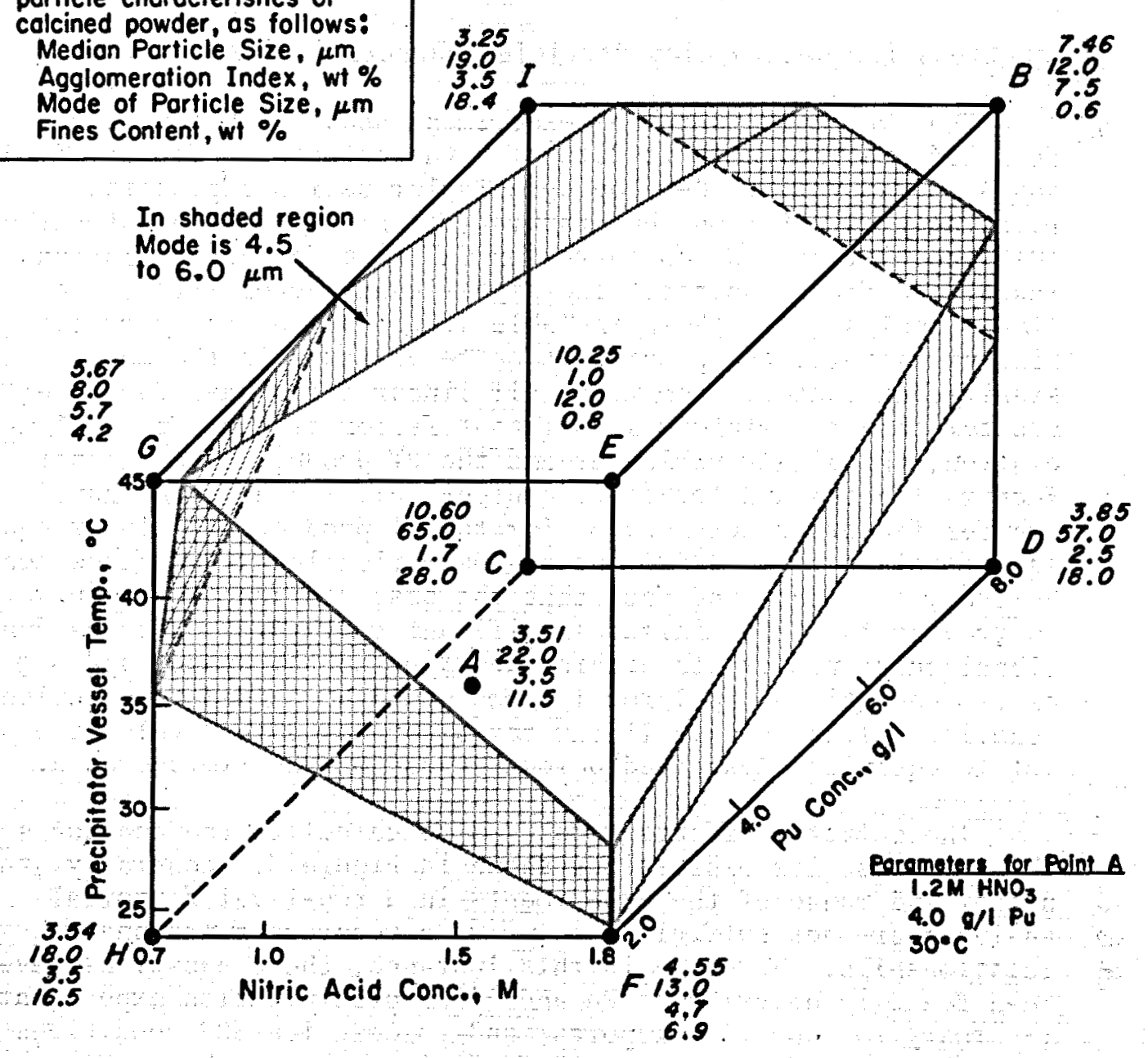

FIGURE 1. Factorial Analyses of $238 \mathrm{Pu}$ 0xalate Precipitation Conditions 
Figure 2 shows SEM photomicrographs for these samples supporting the particle size data. The particle size and extent of agglomeration are different in every instance and vary in concert with the Coulter Counter measurements. As described above, the largest change in morphology occurs along the [111] axis. Very small particles entirely agglomerated into large agglomerates are observed in Sample C, whereas very large unagglomerated particles are observed in Sample E. The appearance of the powder in the middle of the experiment space (Sample A) is typical of SRP ${ }^{238} \mathrm{PuO}_{2}$.

\section{Equations for Determining Particle Characteristics}

The two-level factorial experiment shown in Figure 1 was analyzed statistically to determine the effects of factors $T, P$, and A preparatory to developing a Taylor series expression relating precipitation temperature ( $T$ ), plutonium concentration (P), and nitric acid concentration (A) to mode, agglomeration index, and fines content. The significant factor effects in a linear analysis are shown in Table 4 . Of all of the particle size parameters, the precipitation temperature is the most significant factor. For mode, all linear terms have factor effects greater than the minimum significant factor effect; for agglomeration, the single variables and the PT product have greater factor effects; and for fines content, all linear terms have greater factor effects except for the AT product. A linear equation is sufficient to describe the agglomeration index and fines content. However, for mode, the fact that the observed functional curvature is greater than the minimum significant curvature indicates functional curvature exists within the experimental space, and higher order quadratic or reciprocal terms would be needed to describe mode behavior, although only linear terms were used to develop the parametric equations described below because of the limited data.

These factor effects were used to calculate the constants for the Taylor series expressions shown in Figure 3. General1y, the number and range of the experiments in a two-level factorial analysis are not sufficient to provide rigorous functional

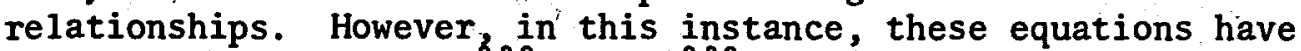
been found to describe ${ }^{238} \mathrm{Pu}$ and ${ }^{239} \mathrm{Pu}$ precipitation experiments (February to June 1975. reports) and to describe SRP conditions (above) with sufficient accuracy to allow them to be applied to SRP production of ${ }^{23}{ }^{8} \mathrm{PuO}_{2}$. Additional experiments are planned both in SRL and SRP to improve these relations. In the meantime, these relations are being used to establish conditions for the control of ${ }^{238} \mathrm{PuO}_{2}$ particle characteristics. 


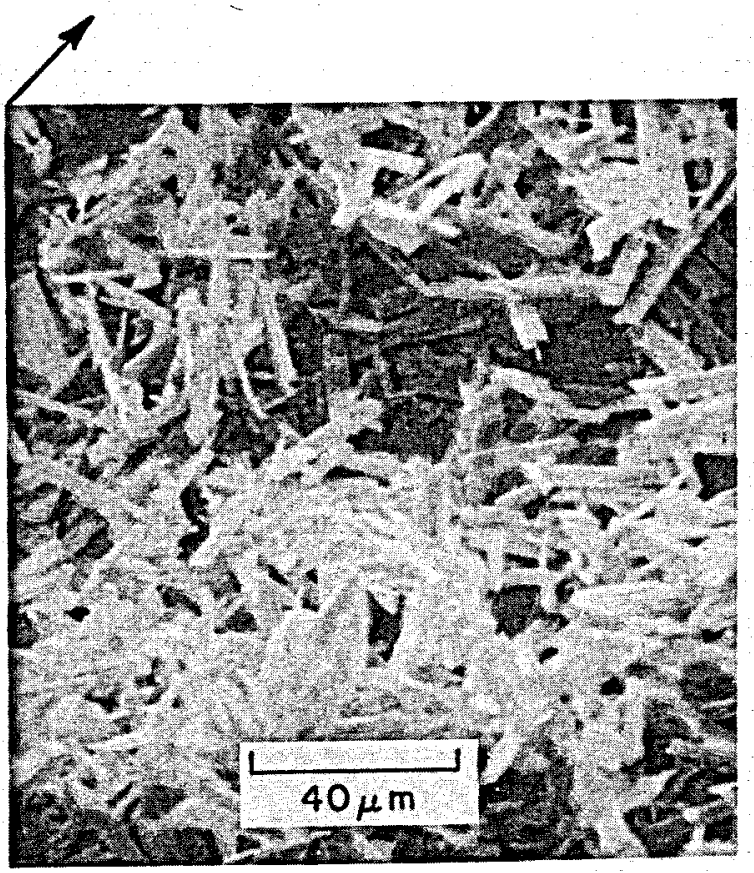

Point G: $0.7 \mathrm{M}\left[\mathrm{H}^{+}\right], 45^{\circ} \mathrm{C}$ Mode $=5.7 \mu \mathrm{m}$

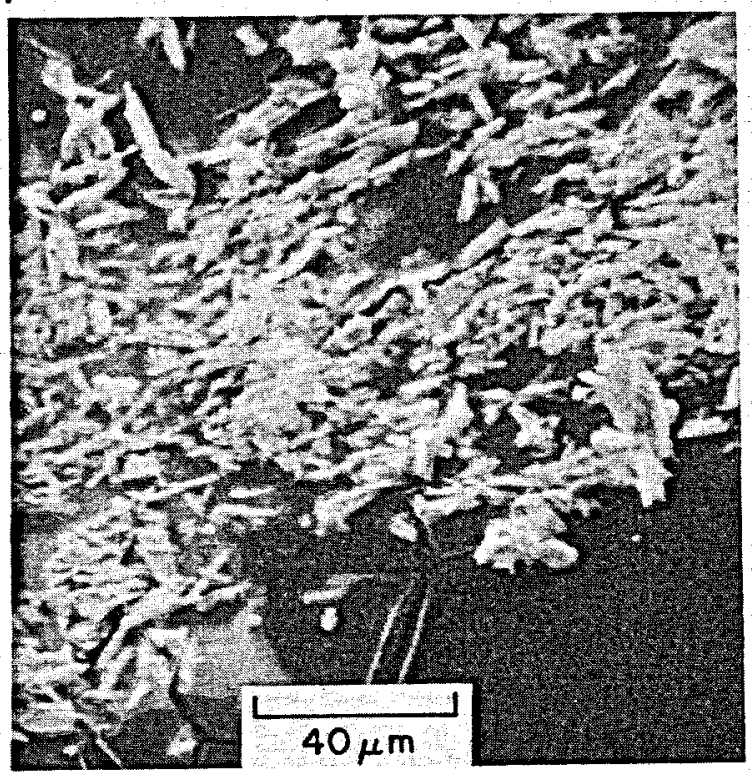

Point H: $0.7 \mathrm{M}\left[\mathrm{H}^{+}\right], 22^{\circ} \mathrm{C}$ Mode $3.5 \mu \mathrm{m}$

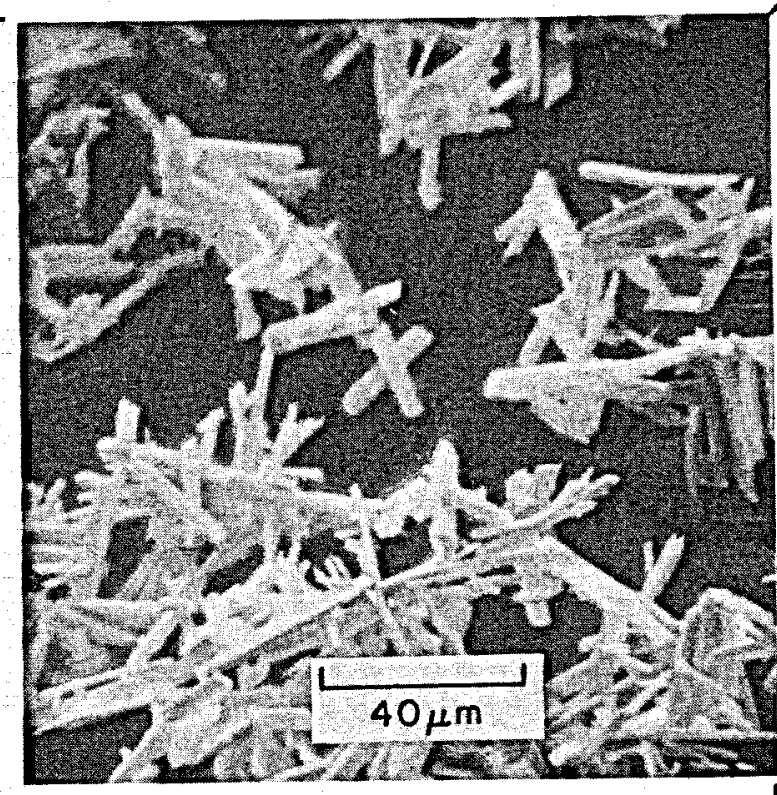

Point E: $1,8 \mathrm{M}\left[\mathrm{H}^{+}\right], 45^{\circ} \mathrm{C}$ Mode $\equiv 12 \mu \mathrm{m}$

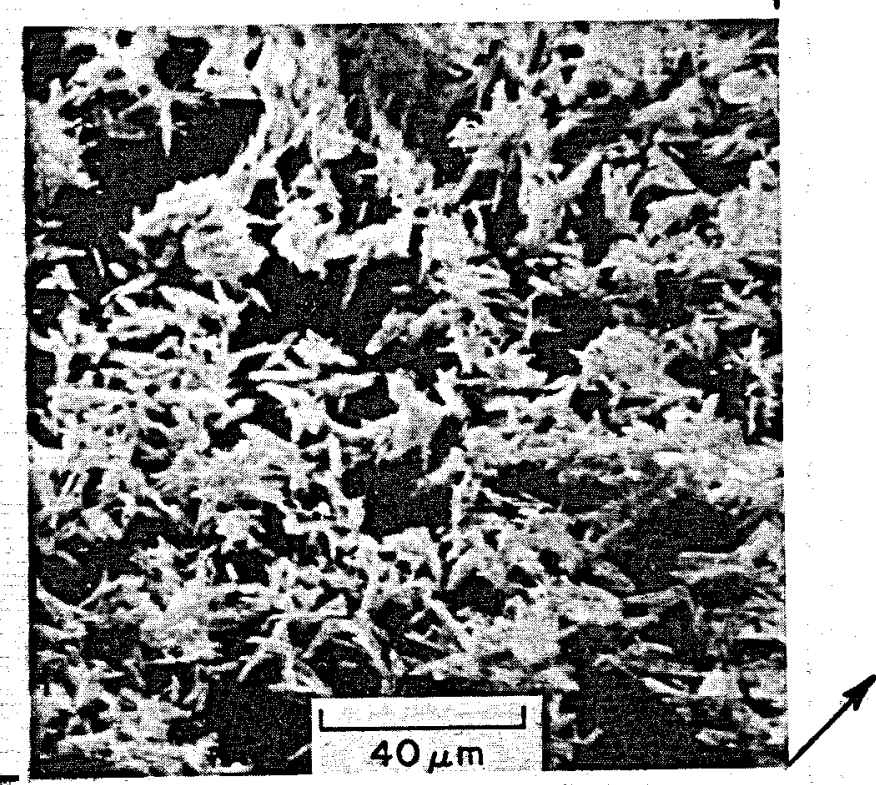

Point F: $1.8 \mathrm{M}\left[\mathrm{H}^{+}\right], 22^{\circ} \mathrm{C}$

a. Precipitates formed under conditions cited in Figure 1, Plane GEFH: ${ }^{238} \mathrm{Pu}$ concentration $=2.0 \mathrm{~g} / 1$.

FIGURE 2. SEM Photomicrographs of ${ }^{238} \mathrm{PuO}_{2}$ Precipitated Under Different Conditions 


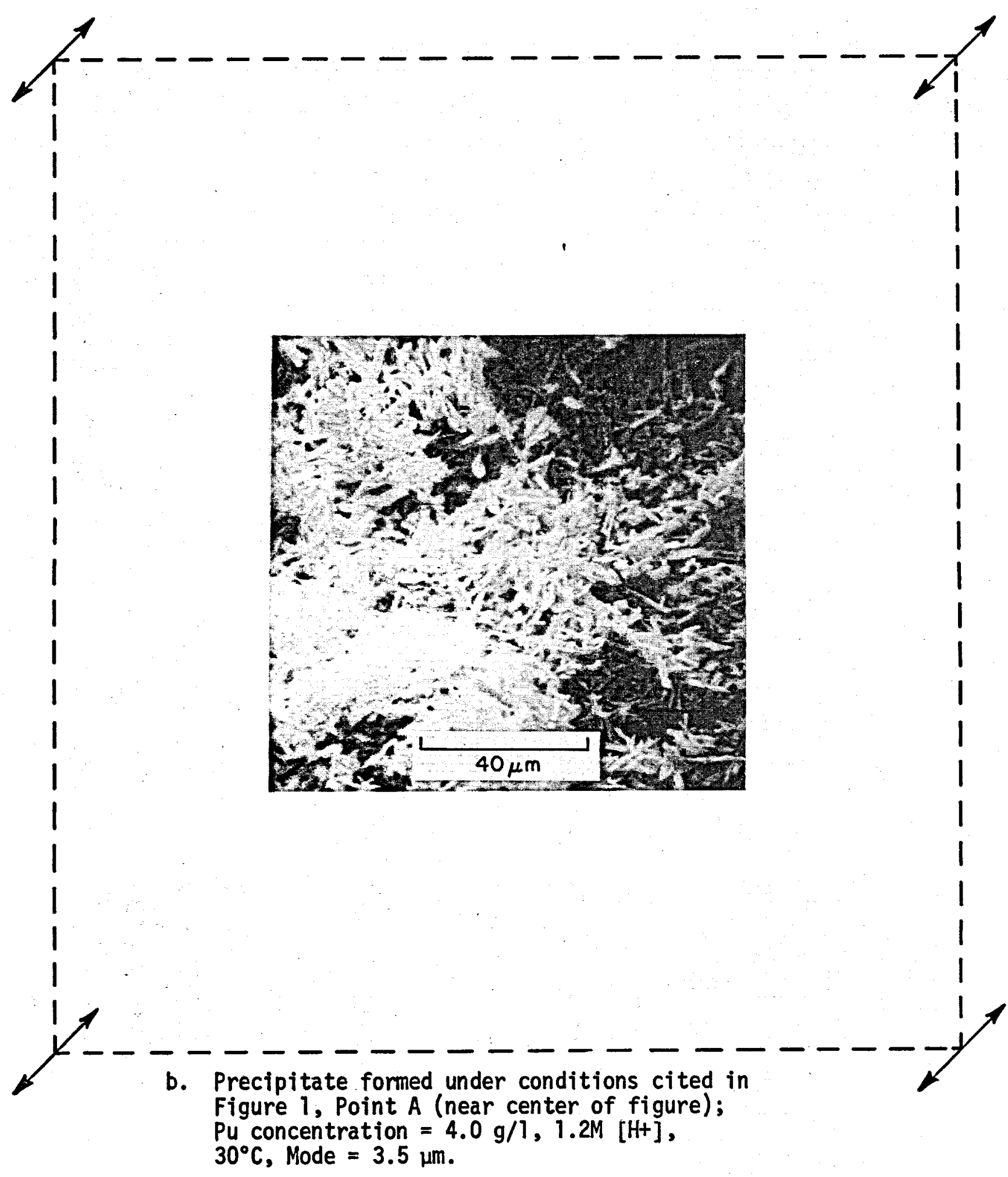

FIGURE 2. Continued. 


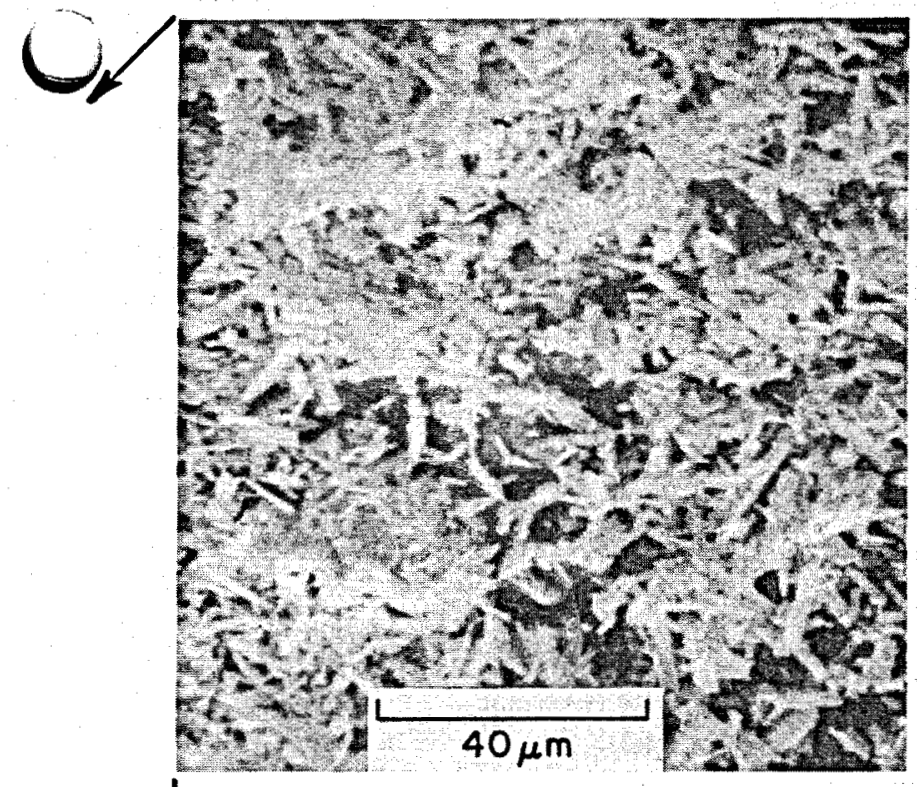
i

$$
\text { Point I: } \begin{aligned}
& 0.7 \mathrm{M}\left[\mathrm{H}^{+}\right], 45^{\circ} \mathrm{C} \\
& \text { Mode }=3.5 \mu \mathrm{m}
\end{aligned}
$$

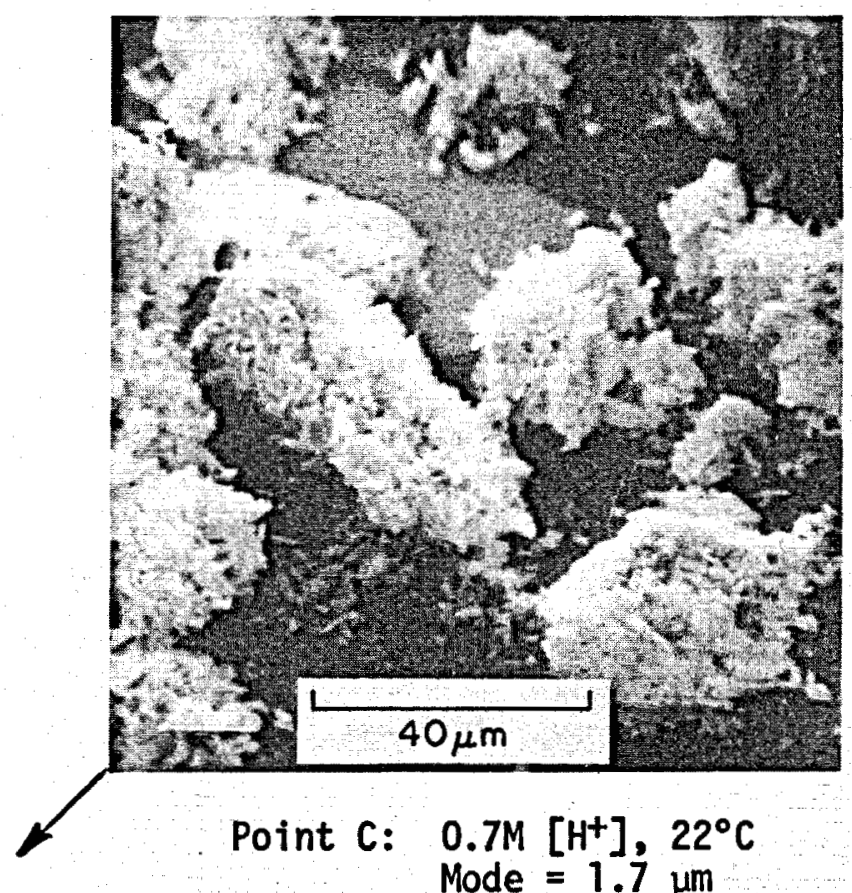

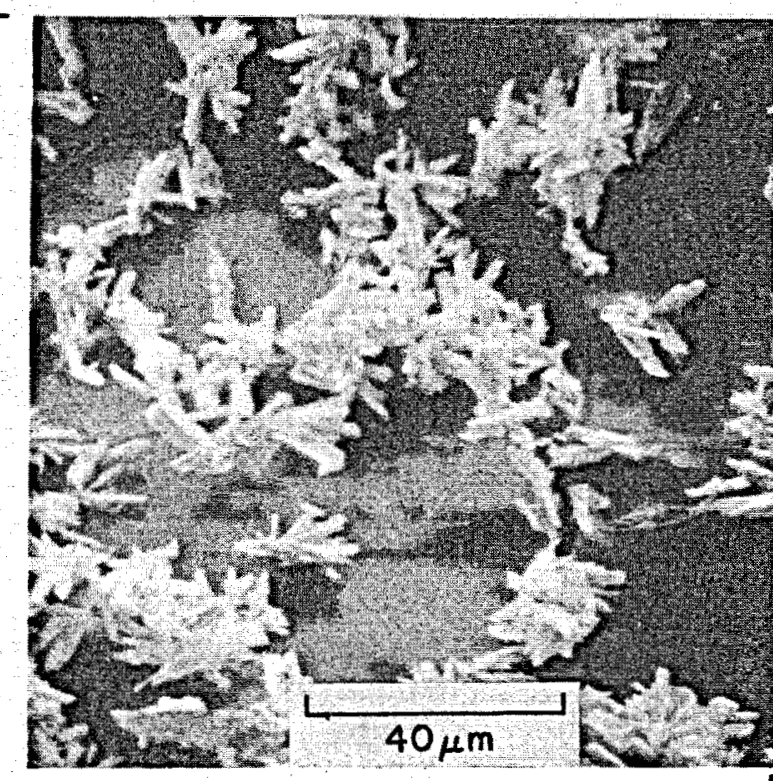

Point B: $1.8 \mathrm{M}\left[\mathrm{H}^{+}\right], 45^{\circ} \mathrm{C}$ Mode $=7.5 \mu \mathrm{m}$

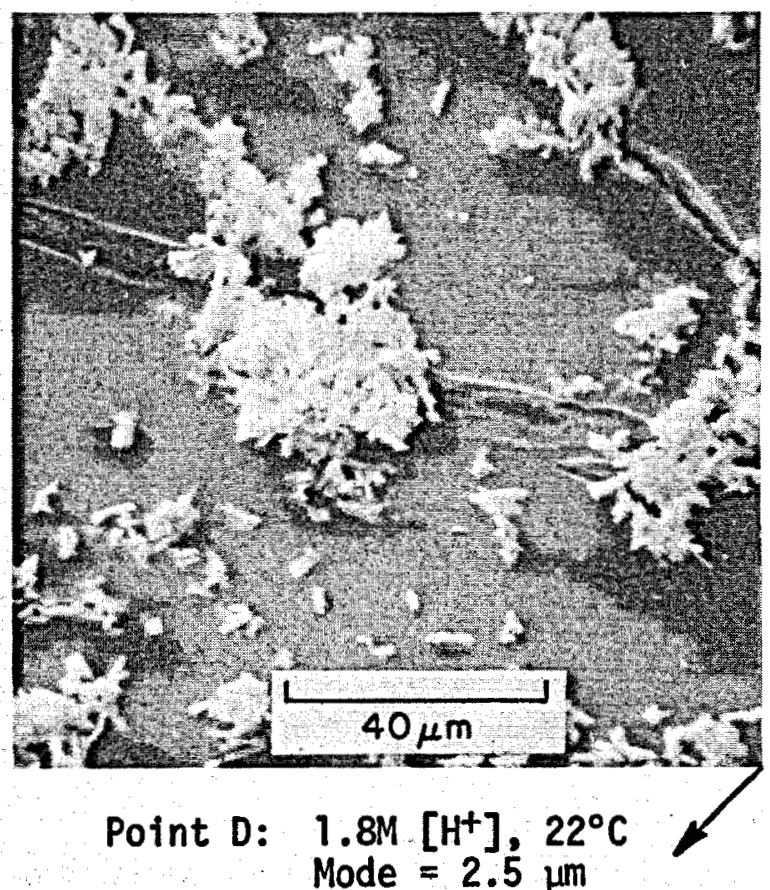

c. Precipitates formed under conditions cited in Figure 1, Plane IBDC; Pu concentration $=8.0 \mathrm{~g} / 1$

FIGURE 2. Continued. 
TABLE 4

Factors Affecting the Precipitation of Plutonium Oxalate

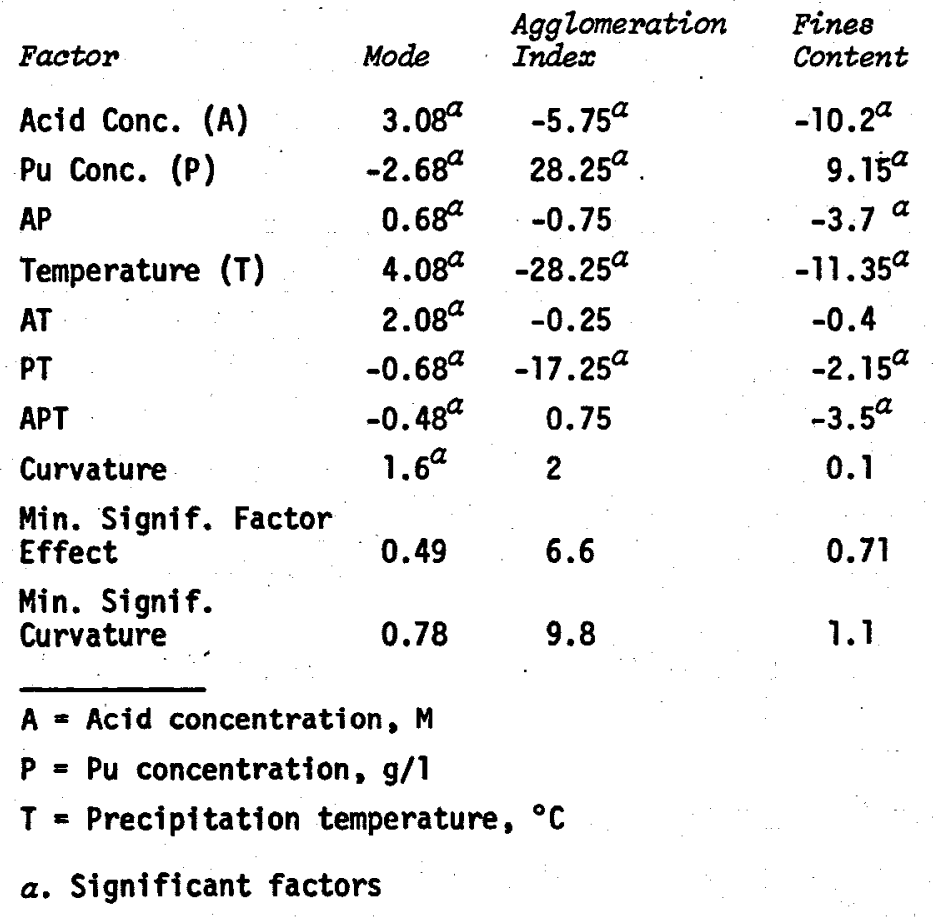

Mode of Particle Size, $\mu \mathrm{m}=4.527-3.796 \mathrm{~A}-0.389 \mathrm{P}-0.0589 \mathrm{~T}+0.218 \mathrm{AP}$ $+0.227 \mathrm{AT}+0.00594 \mathrm{PT}-0.0126 \mathrm{APT}$

Agglomeration Index, wt $\%=6.30-5.23 \mathrm{~A}+13.08 \mathrm{P}+0.0223 \mathrm{~T}-0.250 \mathrm{PT}$

Fines Content, wt $\%=15.3+0.042 A+4.899 P-0.1996 \mathrm{~T}$

- 1.863AP - 0.111AT - 0.0589PT

+0.02205 APT .

$A=$ Nitric acid concentration in feed, $M$

$P=$ Total plutonium concentration in feed, $g / 1$

$T=$ Temperature in precipitator, ${ }^{\circ} \mathrm{C}$

FIGURE 3. Parametric Equations for Mode, Agglomeration Index, and Fines Content 
Any particle size parameter could have been chosen to develop the functional relationship. The agglomeration index and fines content were chosen in addition to mode as most indicative of ball-milling and fabrication response. Fines content was chosen because $2 \mu \mathrm{m}$ is about the ultimate limit obtained on ball milling. Therefore, feed should be larger than $2 \mu \mathrm{m}$ to have a consistent particle size distribution after milling.

The quality of the fit of these equations to the data points on which the equations are based is shown in Table 5 . The range of the functions is between 1 and $12 \mu \mathrm{m}$ for the mode, 0 to $65 \mathrm{wt} \%$ for the agglomeration index, and 0 to $30 \mathrm{wt} \%$ for the fines content. The particle size parameters for all production ${ }^{238} \mathrm{PuO}_{2}$ samples have been within these ranges.

TABLE 5

Quality of Fit of Parametric Equations to Experimental Data for Precipitation of $23{ }^{8} \mathrm{PuO}_{2}$

\begin{tabular}{|c|c|c|c|c|c|c|c|c|c|}
\hline Scomple & $\begin{array}{l}\text { Nitric } \\
\text { Acid, } M\end{array}$ & Pu, $g / l$ & Temp., ${ }^{\circ} \mathrm{C}$ & $\frac{\text { Mode, }}{\text { obs. }}$ & $\frac{\mu m}{\text { Cato. }}$ & $\frac{A I^{a}}{\partial b_{8}}$ & Cate. & $\frac{\text { Fines }}{\text { Obs. }}$ & $\frac{\text { Content, wt } x^{b}}{\text { Catc. }}$ \\
\hline$A^{c}$ & 1.2 & 4.0 & 30 & 3.5 & 4.8 & 22 & 23 & 12 & 12 \\
\hline B & 1.8 & 8.0 & 45 & 7.5 & 7.4 & 12 & 12 & 0.6 & 2.9 \\
\hline c & 0.7 & 8.0 & 22 & 1.7 & 1.7 & 65 & 64 & .28 & 30 \\
\hline D & 1.8 & 8.0 & 22 & 2.5 & 2.5 & 57 & 58 & 18 & 16 \\
\hline$E$ & 1.8 & 2.0 & 45 & 12 & 12 & 1 & 1.5 & 0.8 & -1.2 \\
\hline $\mathbf{F}$ & 1.8 & 2.0 & 22 & 4.7 & 4.7 & 13 & 13 & 6.9 & 8.8 \\
\hline G & 0.7 & 2.0 & 45 & 5.7 & 5.6 & 8 & 7.3 & 4.2 & 6.1 \\
\hline H & 0.7 & 2.0 & 22 & 3.5 & 3.5 & 18 & 18 & 16.5 & 14.5 \\
\hline I & 0.7 & 8.0 & 45 & 3.5 & 3.4 & 19 & 18 & 18 & 16 \\
\hline
\end{tabular}

a. AI = Agglomeration Index, wt \%.

$b$. Fines content is the weight percent of particles of less than 2 um.

c. Not used to establish equations.

Sample A was not used to obtain the equations in Figure 3. This sample represents parameters near the center of the parameter space of Figure 1 and is near the centerline conditions used at SRP. The calculated agglomeration index and fines content agree with the observed values as expected because the factorial analysis indicated linear terms were sufficient to describe parameter interactions. However, the calculated mode is $1.3 \mathrm{\mu m}$ larger than observed and is attributed to the curvature of the mode function. Although the calculated agglomeration index and fines content for 10 to 15 previous 1 aboratory precipitations with ${ }^{239} \mathrm{Pu}$ agreed with measured values, the calculated mode was generally higher than observed in previous precipitations by about $0.5 \mathrm{\mu m}$. Consequently, until additional precipitations are made to refine the expression 
for the mode, the calculated mode using the equation in Figure 3 appears to be about $0.5 \mathrm{\mu m}$ high on the average. This discrepancy is equivalent to about $3^{\circ} \mathrm{C}$ deviation in the precipitator temperature.

\section{Application to SRP Production}

Precipitation temperatures for production were calculated using the equations in Figure 3 to test the applicability of these functions to SRP production and to provide insight into the cause of variation in the feed. Nitric acid and plutonium concentrations in the feed to the precipitator are known and recorded. But precipitation temperatures have not been closely controlled or recorded, because, heretofore, such precise control of particle size characteristics was not required.

The calculated precipitation temperatures corresponding to the measured mode, agglomeration index, and fines content are listed in Table 1. The differences between the three temperatures in many runs are large, probably because:

- The sample generally represents a combination of up to three different precipitations.

- The temperature during feed addition can vary about $10^{\circ} \mathrm{C}$ because of alternating hot and cold water addition to the jacket on the precipitator.

- The temperature of the feed solution varies.

The temperature calculated from the mode is believed to be the most significant of the three because the mode can be determined more accurately than agglomeration index or fines content.

The observations that, in many cases, two or three of the calculated temperatures are nearly the same, the temperatures are in the range thought to have existed, and the SEM microphotographs of the feed correlate with precipitation temperature, all lend credibility to precipitation temperature as the principal cause of variation in the particle size of the feed. The range of calculated temperatures from the measured mode is between 20 and $50^{\circ} . \mathrm{C}$ for both old and problem feed. Because problem feed was precipitated at generally lower acid concentration, the mode for problem feed was generally smaller.

Analysis of the calculated temperatures for new feed provides the best confirmation of the applicability of the equations to SRP conditions. Acid concentration was controlled closely between 1.1 
and $1.3 \mathrm{M}$ for production of new feed beginning in 1975 with Lot HL 301 , and more precise temperature measurement and control were implemented for the last three lots shown in Table 1 . The three calculated temperatures for each of the four runs of Lot HL 301 produced in February (Table 1) are in good agreement and indicate these runs were precipitated between 40 and $60^{\circ} \mathrm{C}$. SEM photomicrographs of these runs (March 1975 report, Figure 20) showed the particles to be unusually large and to vary in size. These observations agreed with measurements made with the Coulter Counter. More importantly, the appearance of the particles for Run 502HA272 was much like that for $a^{239} \mathrm{PuO}_{2}$ precipitation done in the laboratory at $67^{\circ} \mathrm{C}$ (May 1975 report, Figure 1), thereby confirming the calculated high precipitation temperatures.

The agreement between calculated and observed precipitation temperatures for Lots HL 314, HL 315, and HL 316 produced in June 1975 (Table 1) particularly supports the applicability of the equations to SRP production. In these lots, the precipitation temperature was controlled by flowing only $22^{\circ} \mathrm{C}$ water through the jacket of the precipitator. A new temperature controller was installed for these runs. Recorded temperatures increased from about $22^{\circ} \mathrm{C}$ to about $30^{\circ} \mathrm{C}$ during feed addition because the temperature of the feed solution was about 35 to $40^{\circ} \mathrm{C}$ from self-heating of ${ }^{238} \mathrm{Pu}$. The calculated temperatures using the measured mode were between 23 and $28^{\circ} \mathrm{C}$, in agreement with measured temperatures. The agreement among the three calculated temperatures is considered good. Further, SEM photomicrographs show the particles to be about the same for these lots and smaller than for previous lots with larger modes. Additional precipitations are being made at SRP at controlled, but higher, precipitation temperatures to confirm further the applicability of the analysis and to produce acceptable feed with a mode greater than $4.5 \mu \mathrm{m}$.

\section{Control of Production Processes}

On the basis of the above analysis, the required particle size characteristic to produce acceptable feed as defined by LASL is a mode between 4.5 and $6.0 \mathrm{\mu m}$. The agglomeration index and fines content should be between 20 and $50 \mathrm{wt} \%$ and between 0 and 15 wt $\%$, respectively.

The precipitation conditions to meet these specifications are listed in Table 2. SRP plans to continue controlling acid concentration in the feed between 1,1 and $1.3 \mathrm{M}$. However, the wide range of 4 to $7 \mathrm{~g} / 1$ for total plutonium concentration cannot be made more restrictive without a significant production penalty. Consequently, the precipitation temperature may need to be adjusted to maintain the desired mode. Presently temperature control equipment cannot 
control temperature to better than $\sim \pm 5^{\circ} \mathrm{C}$. This $10^{\circ} \mathrm{C}$ maximum variation in temperature can cause a change of $1.5 \mu \mathrm{m}$ in the mode. Installation of equipment to improve the temperature control is being considered.

The equations of Figure 3 were used to calculate the data in Tables 6,7 , and 8 for variation in mode, agglomeration index, and fines content. These tables can be used to select the precipitation temperature for a given acid and plutonium concentration. The precipitation conditions producing unacceptable feed are in italics. The data shown for mode in Table 5 are believed to be high by about $0.5 \mu \mathrm{m}$ because, as described above, the function needs to be refined to include the curvature known to exist in the parameter space. Consequently, precipitation temperatures may have to be raised about $3^{\circ} \mathrm{C}$ from those indicated in Tables 6,7 , and 8 .

TABLE 6

Calculated Precipitation Conditions for Controlling Mode in the-Range 4.5 to $6.0 \mathrm{um}$

Mode of Particle Size, um, at

\begin{tabular}{|c|c|c|c|c|c|}
\hline Acid Conc., $M$ & $\begin{array}{l}\text { Temp. } \\
{ }^{\circ} \mathrm{C}\end{array}$ & $\frac{\text { Various }}{3.75}$ & $\frac{\text { Total Pu }}{5.0}$ & $\frac{\text { Concentr }}{6.0}$ & $\frac{\text { tions, } g /}{7.0}$ \\
\hline 1.1 & 30 & 4.62 & 4.14 & 3.75 & 3.37 \\
\hline 1.2 & 30 & 4.87 & 4.36 & 3.96 & 3.56 \\
\hline 1.3 & 30 & 5.11 & 4.58 & 4.17 & 3.75 \\
\hline 1 & 35 & 5.43 & 4.90 & 4.47 & 4.04 \\
\hline 1.2 & 35 & 5.76 & 5.20 & 4.75 & 4.30 \\
\hline 3 & 35 & 6.09 & 5.50 & 5.03 & 4.56 \\
\hline 1 & 40 & 6.23 & 5.65 & 5.19 & 4.72 \\
\hline 2 & 40 & 6.66 & 6.04 & 5.54 & 5.05 \\
\hline 3 & 40 & 7.08 & 6.42 & 5.90 & 5.38 \\
\hline
\end{tabular}




\section{TABLE 7}

Calculated Precipitation Conditions for Controlling Agglomeration Index in the Range 20 to 50 wt \%

\begin{tabular}{|c|c|c|c|c|c|}
\hline \multirow[b]{2}{*}{ Acid Cone., $M$} & \multirow{2}{*}{ Temp., } & \multicolumn{4}{|c|}{$\begin{array}{l}\text { Aggromeration Index, wt } \% \text { at } \\
\text { Vamious Total Pu Concentrations, } g / l\end{array}$} \\
\hline & & 3.75 & 5.0 & 6.0 & 7.0 \\
\hline 1.1 & 30 & 22.1 & 29.1 & 34.7 & 40.3 \\
\hline 1.2 & 30 & 21.6 & 28.6 & 34.2 & 39.8 \\
\hline 1.3 & 30 & 21.1 & 28.1 & 33.7 & 39.2 \\
\hline 1.1 & 35 & 17.6 & 23.0 & 27.3 & 31.6 \\
\hline 1.2 & 35 & 17.0 & 22.5 & 26.8 & 31.1 \\
\hline 1.3 & 35 & 16.5 & 21.9 & 26.3 & 30.6 \\
\hline 1.1 & 40 & 13.0 & 16.8 & 19.9 & 23.0 \\
\hline 1.2 & 40 & 12.5 & 16.3 & 19.4 & 22.5 \\
\hline 1.3 & 40 & 11.9 & 15.8 & 18.9 & 22.0 \\
\hline
\end{tabular}

TABLE 8

Calculated Precipitation Conditions for Controlling Fines Content $a$ to $<15$ wt $\%$

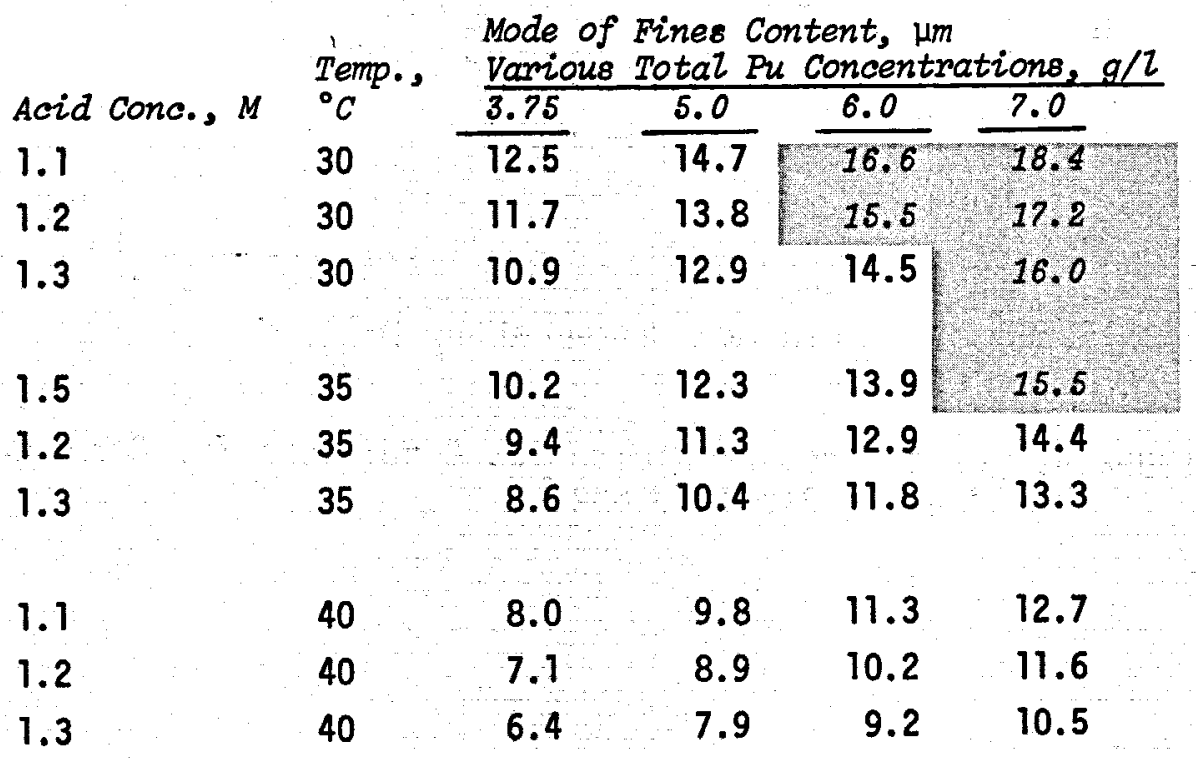

a. Weight percent of particles of less than $2 \mu \mathrm{m}$. 
Figure 4 shows in a different format the calculated precipitation conditions for constant mode. Figure 5 lists the boundary conditions for this analysis.

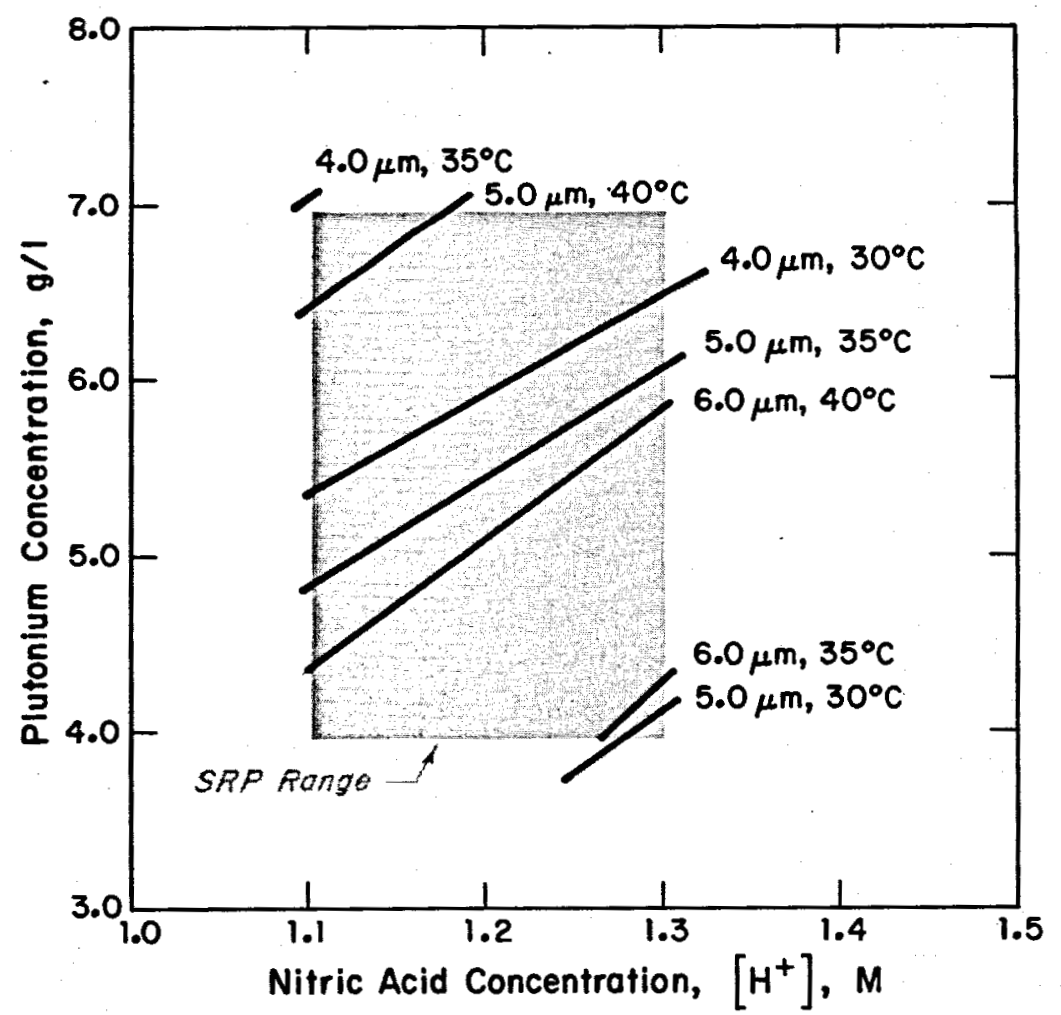

FIGURE 4. Calculated Precipitation Conditions for Constant Mode of Particle Size 
1. Reverse strike precipitation of Pu(III); valence control with ascorbic acid and hydrazine.

2. $0.9 \mathrm{M} \mathrm{H}_{2} \mathrm{C}_{2} \mathrm{O}_{4}$ solution in precipitator with $0.2 \mathrm{M}$ excess in total $\mathrm{H}_{2} \mathrm{C}_{2} \mathrm{O}_{4}$.

3. $22^{\circ} \mathrm{C} \leqslant T \leqslant 45^{\circ} \mathrm{C}$ in precipitator.

4. Composition of feed solution added to precipitatior:

$0.7 \leqslant\left[\mathrm{H}^{+}\right] \leqslant 1.8 \mathrm{M}$ and $2 \mathrm{~g} / 1 \leqslant[\mathrm{Pu}] \leqslant 8 \mathrm{~g} / 1$.

5. Feed addition rate of 9.5 to $11.0 \%$ /minute;

$+10 \%,-5 \%$.

6. Precipitate calcined to ${ }^{23}{ }^{8} \mathrm{PuO}_{2}$ at $735^{\circ} \mathrm{C}$ for 2 hours.

7. Particle size measurement by Coulter Counter technique with 1.5 minutes of ultrasonic dispersion.

FIGURE 5. Boundary Conditions for Precipitation Functions for Control of Particle Size of ${ }^{238} \mathrm{PuO}_{2}$

Program

Experiments are proceeding in HB Line to improve temperature control and to confirm the applicability of this analysis at higher temperatures under production conditions. Runs thought to be acceptable on the basis of particle size analysis at SRL will be shipped to LASL to confirm acceptable fabricability. Laboratory precipitations will continue in order to obtain sufficient statistics for a least-squares derivation of more precise functional relations. 


\section{MULTI-HUNDRED WATT PROCESS DEMONSTRATION}

\section{ULTRASONIC CLEANING ON IRIDIUM-CLAD SIMULANT SPHERES}

No effects that could disqualify ultrasonic decontamination methods were observed on either Multi-Hundred Watt Post Impact Shell Assemblies (PISA) or two simulant spheres. The test conditions and resulting effects on the PISA and simulants are shown in Table 9.

The major concern was cracking of the sphere and/or the generation of fines as a result of the ultrasonic vibration. Neither of these effects were observed on the simulant materials. The test conditions were more severe than will be encountered in the PuFF facility, as a 1000-watt ultrasonic generator was used whereas the PuFF cleaners utilize only 300 watts of power. A full-scale test of an iridium-encapsulated ${ }^{238} \mathrm{PuO}_{2}$ sphere is required, however, to prove conclusively that no deleterious effects result from ultrasonic cleaning. This test will be made in the Plutonium Experimental Facility (PEF), with an ultrasonic cleaner identical to the one proposed for the PuFF production facility.

TABLE 9

Effect of Ul trasonic Power on PISA Components

\begin{tabular}{|c|c|c|c|}
\hline Component & Simelont & Test Condition & Effect \\
\hline Ir Hemishells & - & $\begin{array}{l}1000 \text { watts of ultrasonic cleaning } \\
\text { power for } 30 \mathrm{~min} \text { at } 70^{\circ} \mathrm{C} \text { with } \\
\text { electrodeplating (current density } \\
220 \times 10^{-4} \mathrm{~mA} / \mathrm{m}^{2} \text { ) }\end{array}$ & $\begin{array}{l}\text { No visible effects on } \\
\text { Ir, } 8 \times 10^{-3} \text { wt } x \\
\text { weight loss. }\end{array}$ \\
\hline Bare PPO ${ }^{\alpha}$ Sphere & $\begin{array}{l}\text { Cracked lava } \\
\text { sphere }\end{array}$ & 1000 watts for $30 \mathrm{~min}$ & $\begin{array}{l}\text { Sinall crack growth } \\
\text { and pitting. }\end{array}$ \\
\hline Bare PPO Sphere & $\begin{array}{l}\text { Monolithic } \mathrm{ThO}_{2} \\
\text { sphere }\end{array}$ & 1000 watts for $30 \mathrm{~min}$ & $\begin{array}{l}\text { No visible effects or } \\
\text { weight loss; no crack- } \\
\text { ing or pitting. }\end{array}$ \\
\hline Ir Encapsulated PPO Sphere & $\begin{array}{l}\text { Stainless steel } \\
\text { encapsulated } \\
\text { sphere }\end{array}$ & 1000 watts for $30 \mathrm{~min}$ & $\begin{array}{l}\text { No change; no observable } \\
\text { fines generated. }\end{array}$ \\
\hline Ir Encapsulated PPO Sphere & $\begin{array}{l}\text { Stainless stee } 1 \\
\text { encapsulatsd } \\
\mathrm{ThO}_{2} \text { sphere }\end{array}$ & 1000 watts for $30 \mathrm{~min}$ & $\begin{array}{l}\text { No change, no cracking; } \\
\text { fines generation could } \\
\text { not be determined } \\
\text { because of abrasion of } \\
\mathrm{ThO}_{2} \text { during loading. }\end{array}$ \\
\hline
\end{tabular}

a. $\mathrm{PPO}=$ pure plutonium oxide 


\section{EFFECT OF SHARD AGING ON MICROSTRUCTURE OF HOT-PRESSED PPO PELLETS}

Metallographic examination of a pellet fabricated from LASL shards which had been aged for 14 months showed no effects of helium release during hot pressing. This study, part of a program to establish limits on storage times of feed materials for the PPO sphere fabrication process, indicates that the shards can be stored for over a year without producing microstructural damage in a hot-pressed product. The microstructure of the $86.2 \%$ dense pellet (MHP-38) was similar to that of the approximately $90 \%$ dense pellets previous1y pressed from shards aged 2,4 , and 8 months (August 1974 report, $p$ 11).

Pellet MHP-38 was formed from shards of less than $125 \mu \mathrm{m}$ produced at LASL using calcined oxalate-base ${ }^{238} \mathrm{PuO}_{2}$. The shards were made by cold pressing the degassed and milled powder into compacts which were broken up and fired for 3 hours at $1075^{\circ} \mathrm{C}$. The shards were stored 14 months before hot pressing at 5000 psi and $1505^{\circ} \mathrm{C}$ into a 0.38 -in.-dia by 0.17 in.-thick pellet. The pellet was heat-treated at $1440^{\circ} \mathrm{C}$ (February 1975 report, p 25).

Metallographic examination of Pellet MHP-38 showed a uniform structure of somewhat finer grains than before, with pores both within grains and on grain boundaries (Figure 6). The pellet appeared more susceptible to material pul lout during etching than the previous pellets, probably because of the lower density. No change in pore distribution that could be attributed to release of helium accumulated during shard storage was evident. A few large cracks in the specimen were seen.

This concludes the work projected to establish effects of shard storage on hot-pressed pellet microstructures.

\section{EFFECT OF TEMPERATURE ON SHARD MORPHOLOGY}

Scanning electron photomicrographs show that LASL shards (Lot BND-229) made from problem feed sintered at a lower temperature than SRL shards (Lot S-20) made from new feed. The morphology of the LASL shards heat-treated at 1150 and $1200^{\circ} \mathrm{C}$ (Figure 7) has a surface rounding and coarsening of the structure similar to the SRL shards heat-treated at a higher temperature of $1300^{\circ} \mathrm{C}$ (July 1975 report). Shards from SRL Lot S-20 heat-treated at $1175^{\circ} \mathrm{C}$ and below showed less sintering. The structural differences were probably due to differences in the as-received particle size of the two feeds. The mode of the particle size of SRL Lot S-20 feed was $10 \mu \mathrm{m}$, whereas LASL Lot BND-229 had a range of modes of particle sizes of 2 to $4 \mu \mathrm{m}$. 


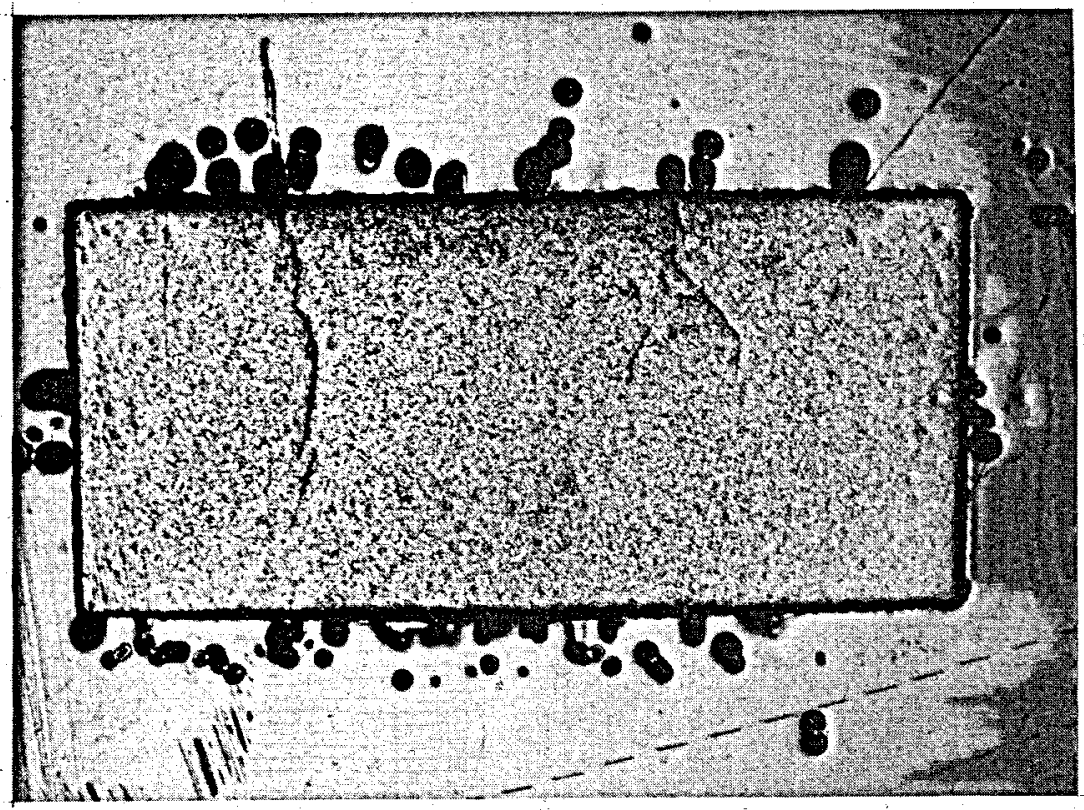

$1-2 \mathrm{~mm} \rightarrow-1$

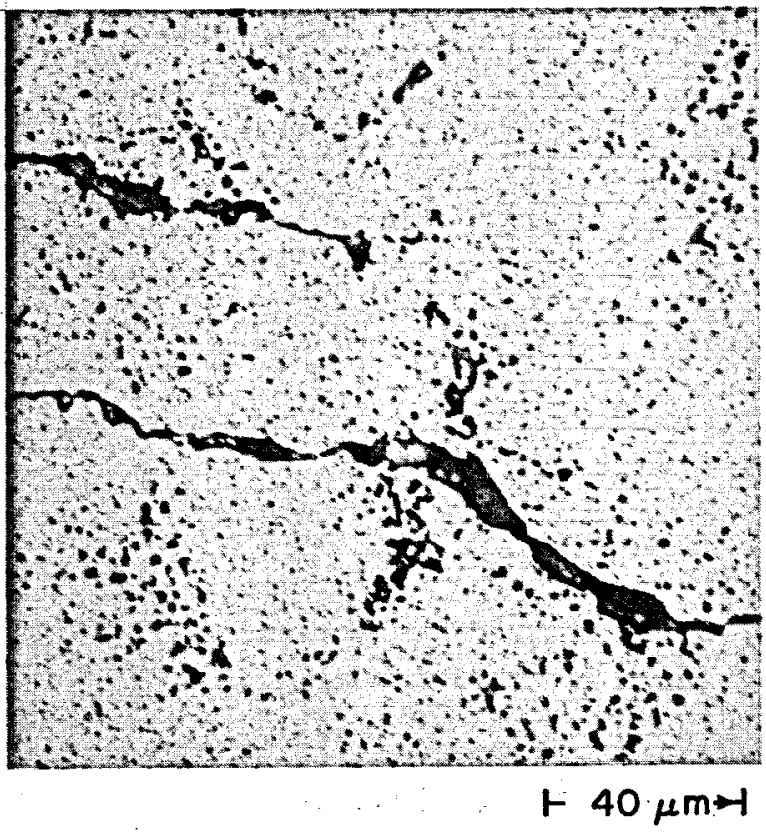

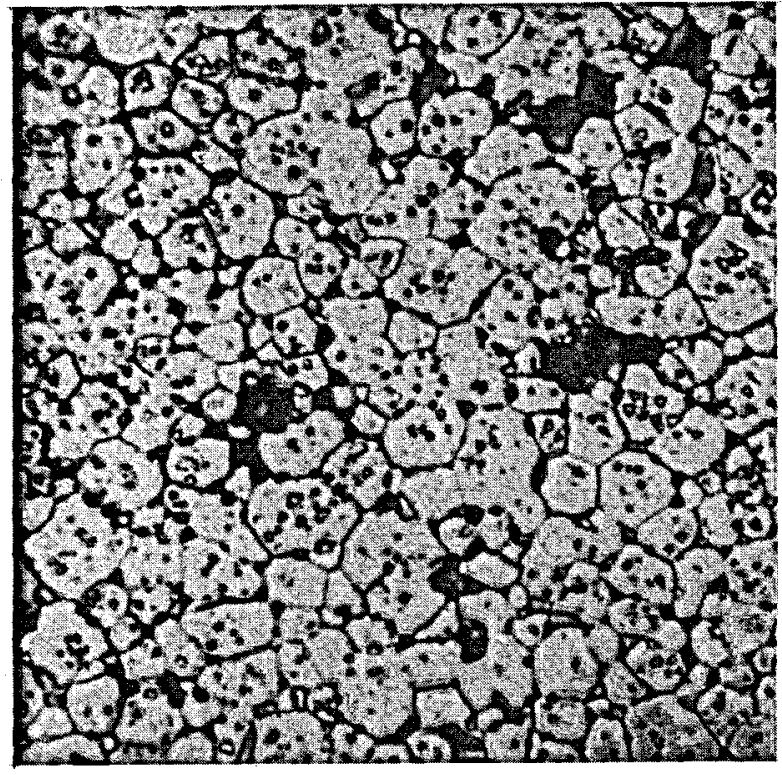

$120 \mu \mathrm{m}+1$

FIGURE 6. Microstructures of Hot-Pressed Pellet MHP-38 from 14-Month Aged Shards 

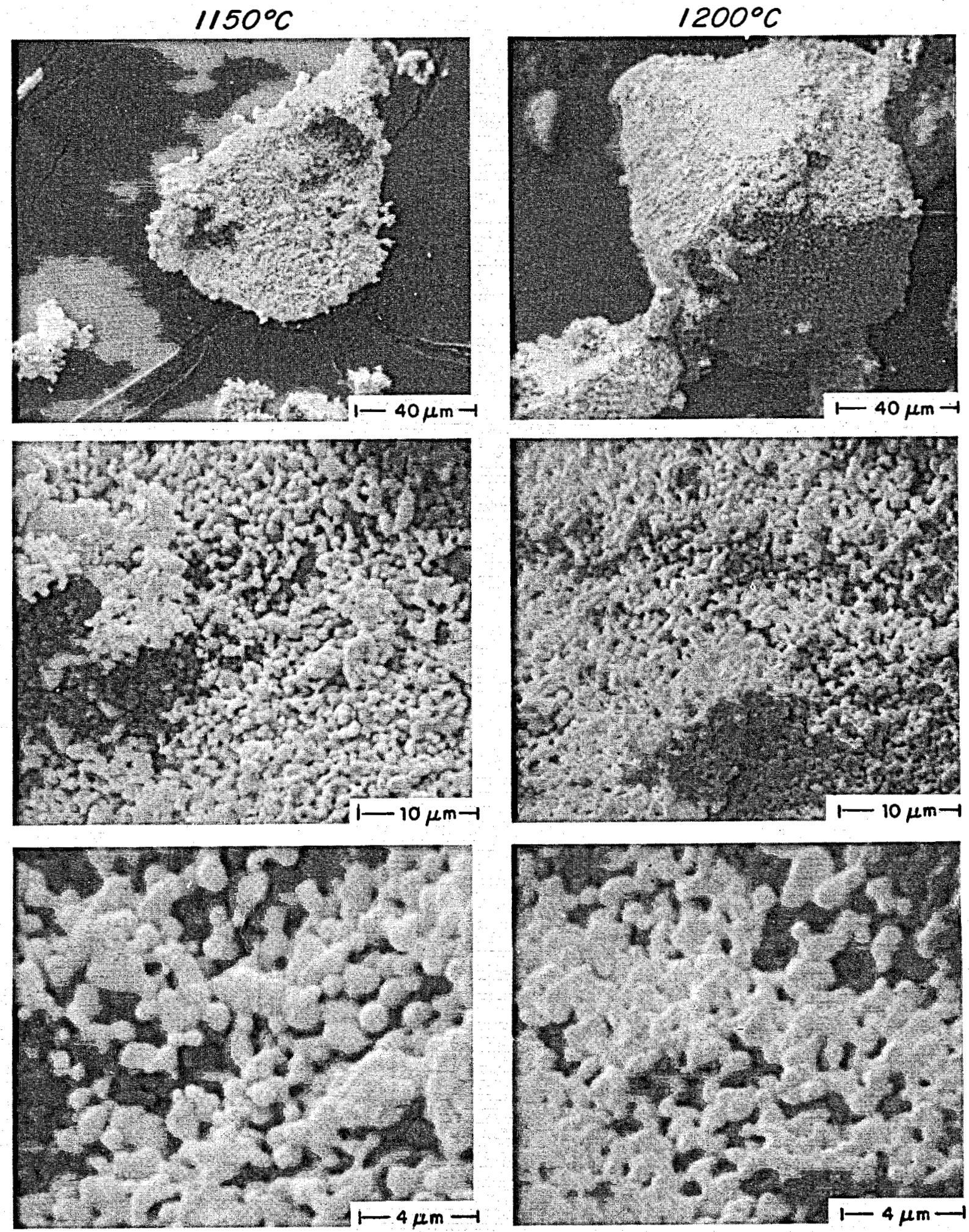

FIGURE 7. SEM Photomicrographs of LASL Lot BND-229 Shards Sintered at 1150 and $1200^{\circ} \mathrm{C}$ 
S1ight differences in the morphology of LASL Lot BND-229 shards caused by the $50^{\circ} \mathrm{C}$ difference in the temperature $(1150$ and $1200^{\circ} \mathrm{C}$ ) can be observed at high magnification (5000X, Figure 7). The $1150^{\circ} \mathrm{C}$ shards have individual particles which are nearly round with bonding and some neck growth between particles. Larger necks between particles can be seen in the shards heated to $1200^{\circ} \mathrm{C}$. This additional sintering at $1200^{\circ} \mathrm{C}$ could account for the fact that die closure was not achieved during the 20 minutes of pressing in hot-press experiment MHP-39 with LASL Lot BND-229 shards heated at $1200^{\circ} \mathrm{C}$ as feed (March 1975 report, p 14). Die closure was achieved in about 20 minutes of pressing in hot-press experiment MHP-27 with LASL Lot BND-229 shards heated at $1150^{\circ} \mathrm{C}$ as feed (January 1975 report, $p$ 9). These results indicate that temperature gradients of only $50^{\circ} \mathrm{C}$ during heating of the shards could affect product quality. The sintering temperature for the final process will be selected to provide shards with correct properties and controlled within $\pm 25^{\circ} \mathrm{C}$, as necessary, to ensure product reproducibility. 


\section{MILLIWATT PROCESS DEVELOPMENT}

\section{SHARD FABRICATION PROCESS}

A process for the fabrication of shards for the Milliwatt Radioisotopic Thermoelectric Generator Program (Milliwatt) was developed which minimizes the fines content. Presintering of the pellets before breakup produces strong shards with smooth cleavage faces and a minimum of asperities (surface roughness points). However, the packing density of these shards is marginal, and further optimization of the flowsheet is required to improve the packing density.

\section{Development of Shard Process}

The first flowsheet investigated produced shards with the desired density, particle size, and grain size (September 1974 report). However, there was an undesirably high percentage of shards of less than 53 . $\mathrm{m}$, which would require recycling (October 1974 report). It was also anticipated that the large amount of surface asperities might produce an unacceptably high fines content from impact or vibration in service. This flowsheet was similar to the Multi-Hundred Watt (MHW) shard process, with the following deviations: the cold-press pressure was 100,000 psi; the shards were crushed to less than $500 \mu \mathrm{m}$, and the particles of less than $53 \mu \mathrm{m}$ were removed by sieving before the 53 through $500 \mu \mathrm{m}$ portion was sintered at $1650^{\circ} \mathrm{C}$ for 10 hours (F1owsheet $\mathrm{I}$, Figure 8).

This process was modified to omit the sieving of the less than $53 \mu \mathrm{m}$ portion prior to sintering in an effort to reduce the percentage of once-through recycle (Flowsheet II, Figure 8). Although the amount of recycle was substantially reduced (Table 10), the shards produced also had a large amount of surface asperities and fines (Figures 9 and 10; December 1974 report, Figure 17).

An attempt was made to minimize asperities and fines content by sintering the cold-pressed pellets for 3 hours at $1175^{\circ} \mathrm{C}$ to strengthen them prior to breakup (Flowsheet III, Figure 8). This presintering gave pellets of approximately $80 \%$ of theoretical density. These pellets broke into very acicular shards with exterior morphologies similar to hydroxide shards (Figures 9 and 10). Strength was increased to the extent that there was no 
evidence of shard rounding from abrasion after breakup. The smooth cleavage faces resulted in the desired minimal surface roughness after the $1650^{\circ} \mathrm{C}$ sintering (Figure 10).
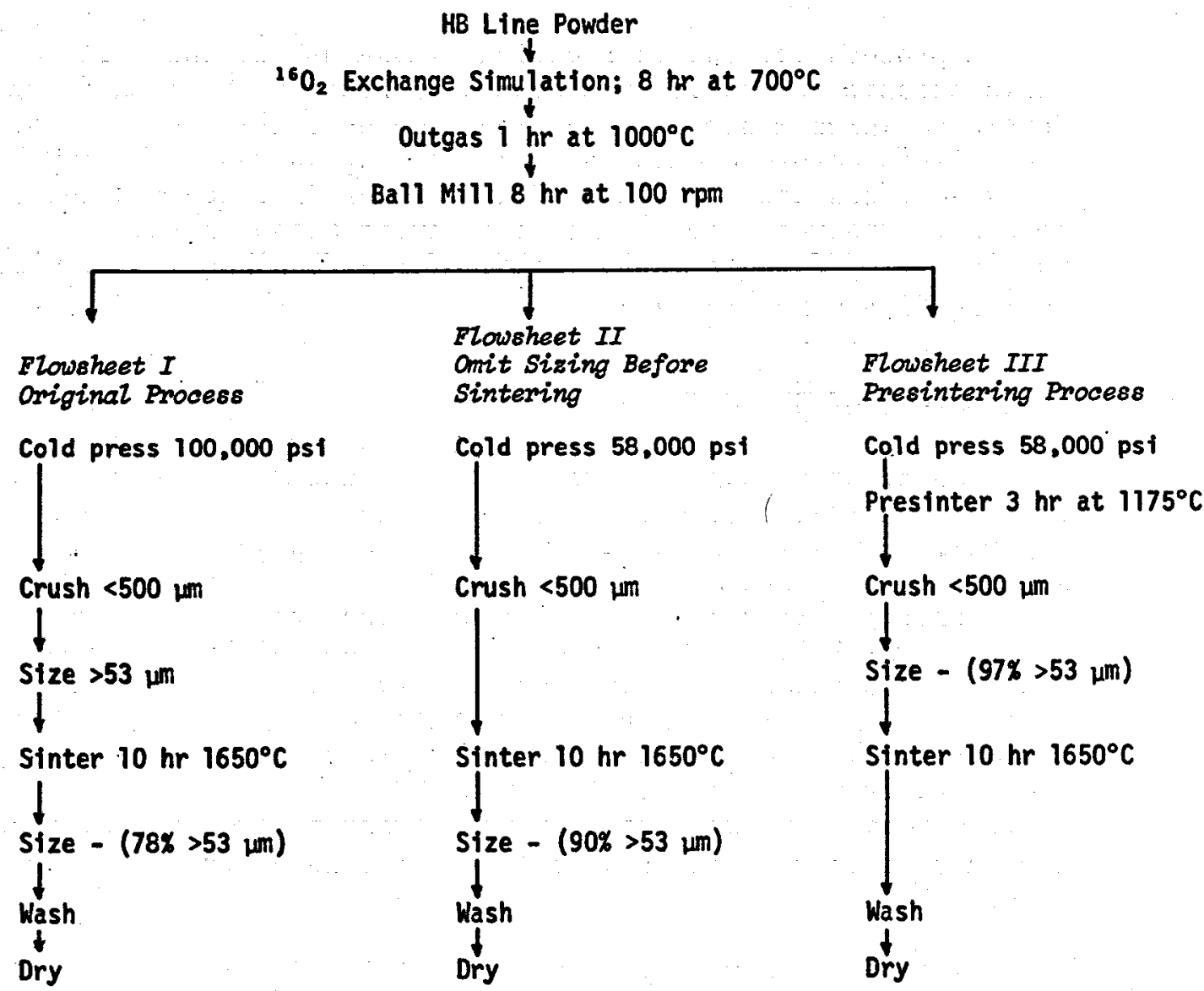

FIGURE 8. Milliwatt Shard Process Flowsheets 


\section{TABLE 10}

Summary of Milliwatt Flowsheet Study

$$
\text { Lot No.: } \begin{array}{lll}
\text { Flowsheet } I^{a} & \begin{array}{l}
\text { Flowsheet II } \\
\text { S26-SS }
\end{array} & \begin{array}{l}
\text { Flowsheet III } \\
\text { S26-PSS }
\end{array}
\end{array}
$$

Recycle fraction, once through, $\%$
22

6.7

95

29

$-\ldots 93$

$-\quad 997$

9
96

33

Fines content $<5 \mu \mathrm{m},{ }^{e} \mu \mathrm{g} / \mathrm{g}$

Fines content $5-10 \mu \mathrm{m}, e \mathrm{~g} / \mathrm{g}$

Number of operations $f$
10

7.05

5.4

95

27

$93 \quad 8.2$

3

0.53

$8 \quad 9$

a. September 1974 report, p 12.

b. Tap densities measured using ASTM Standard B-527-70 modified for small sample size. Estimated accuracy $\pm 5 \%$. Vibrational packing methods, such as are detalled in the text, may result in higher packing densities.

c. Reference 1.

d. Hilliard's intercept method ${ }^{2}$ multiplied by Fullman's Factor3. (1:5) for equiaxed grains.

e. Nominal $10 \mu \mathrm{m}$ screen; actual opening is $7.75 \mu \mathrm{m}$. Nominal 5 um screen; actual opening is $5.09 \mu \mathrm{m}$.

f. Omits outgassing. 
Flowsheet II

PPO Type Process

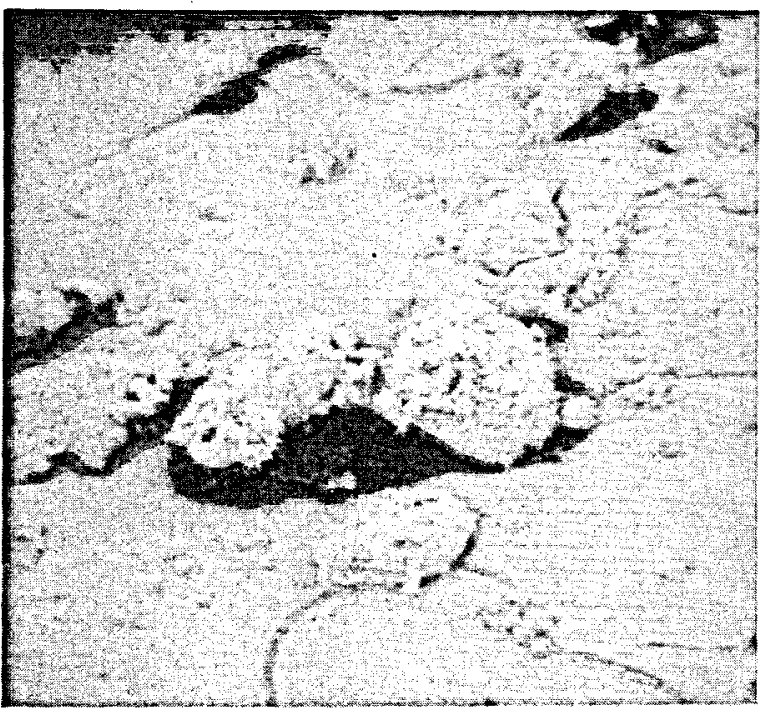

$\leftarrow-100 \mu \mathrm{m} \rightarrow-1$

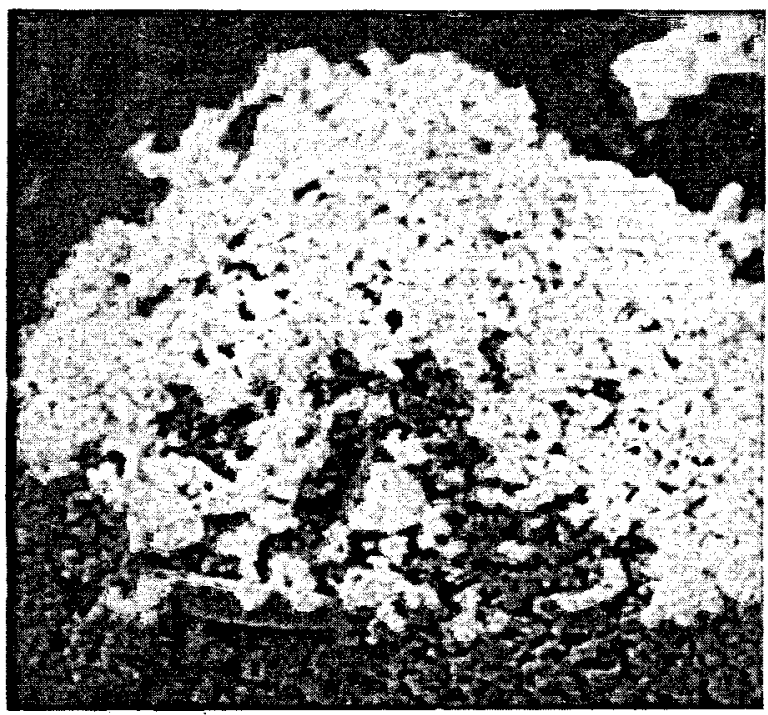

$\leftarrow 20 \mu \mathrm{m} \rightarrow-1$
Flowsheet III

Presintered Process

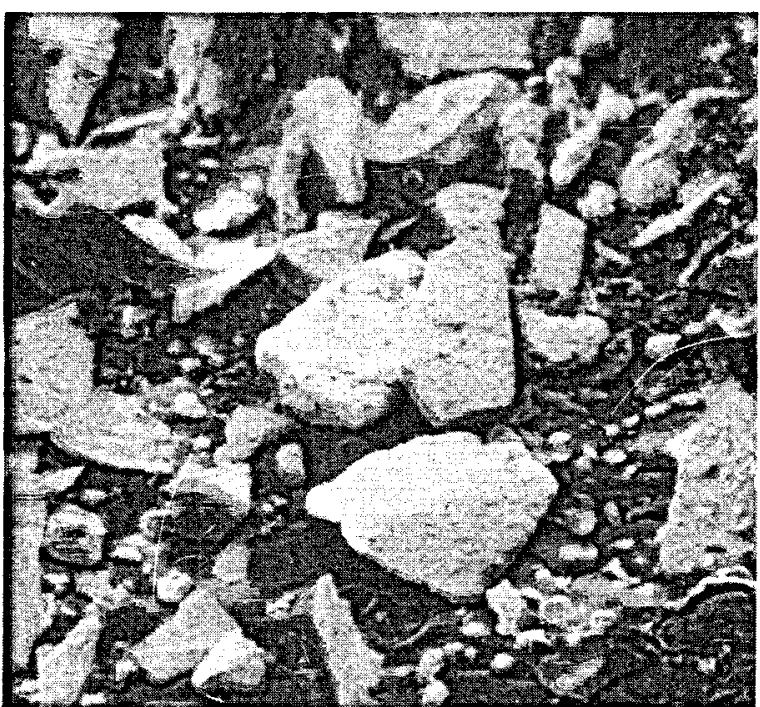

$1 * 400 \mu \mathrm{m} \rightarrow-1$

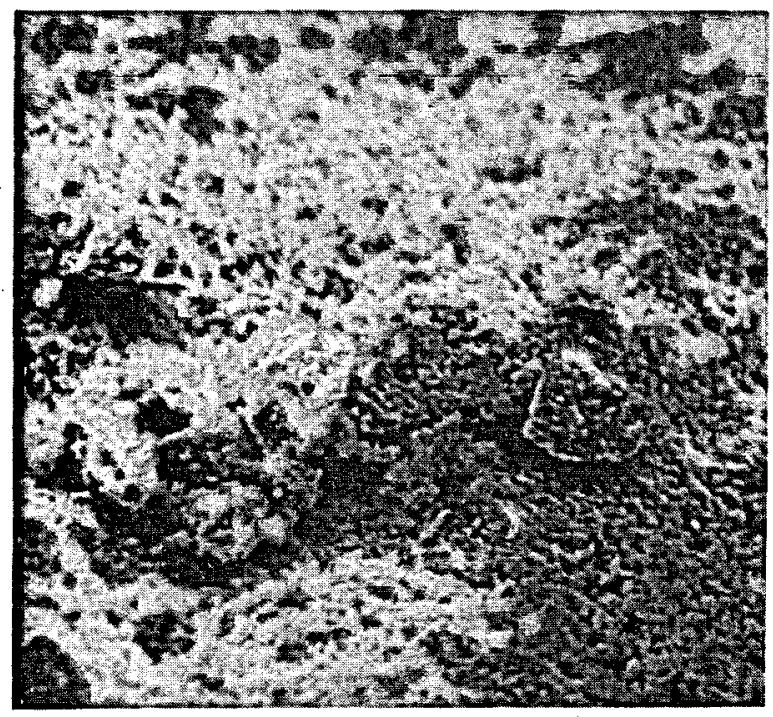

$\leftarrow-20 \mu \mathrm{m} \rightarrow-1$

FIGURE 9. Structure of Milliwatt S-26 Shards Before $1650^{\circ} \mathrm{C}$ Sintering 


\section{Fines Content}

The results of the Mound Laboratory (ML) fines measurement technique for analyzing shards made by Flowsheets II and III are shown in Table 10. Samples from Flowsheet I were not analyzed because the fines measurement technique was not available at the time the shards were fabricated. It was expected that the fines contents from Flowsheets I and II would be similar. The fines content of the presintered shards (Flowsheet III) compared favorably with hydroxide shards produced at ML. Typical values for ML Milliwatt shards were 20 to $40 \mu \mathrm{g} / \mathrm{g}$ of fines of 1 ess than $5 \mu \mathrm{m}$, and 4 to $6 \mu \mathrm{g} / \mathrm{g}$ of fines of 5 to $10 \mu \mathrm{m}$.

\section{Packing Density}

Shards made from any one of the three flowsheets may be loaded to the required minimum power density. Shards by Flowsheet III require vibration by an electrical vibrator, while shards by Flowsheets I or II should require only hand tapping.

The successful packing of Type I shards was detailed in the September 1974 report. Test loading of the Type II shards was not considered necessary, because their tap density is higher than that of Type I shards (Figure 11). Type III shards have a relatively low tap density because of their irregular shape, which necessitated the packing test described below.

A 3.5 W $\mathrm{W}_{\text {th }}$ Milliwatt liner capsule (obtained from Mound Laboratory) was loaded with $8.8 \mathrm{~g}$ of SRL Batch S-26-PSS oxalatebased presintered shards $(53$ to $500 \mu \mathrm{m})$ and $0.4 \mathrm{~g}$ of yttrium metal chips (from Research Chemicals Corp., Phoenix, Arizona). Hand tapping of the liner was not sufficient to produce the required packing density. Liner rim-to-shard clearance was $0.077 \mathrm{in.,}$ or $0.023 \mathrm{in.}$ less than the minimum permissible clearance of $0.100 \mathrm{in}$.

A second $3.5 W_{\text {th }}$ liner (from reject ML Lot 4-4, No. 60-MLB) was secured to a small 110 VAC vibrator (Sensonics, Inc., Long Island, New York) attached to a variable voltage transformer. $0.4 \mathrm{~g}$ of yttrium chips were placed in the container, followed by $8.6 \mathrm{~g}$ of S-26-PSS shards $(8.6 \mathrm{~g}$ is a typical lower limit for MRC loading of hydroxide-based shards). The voltage applied to the vibrator was cycled ten times between 40 and 110 volts. The liner shim was installed and gently pressed while the voltage was again cycled. The resulting liner rim-to-shard clearance was 0.112 in., or 0.012 in. larger than the minimum permissible. 
The capsule was unloaded, and the process was repeated using $8.8 \mathrm{~g}$ of shards, which is a typical upper limit for ML loadings. The resulting liner rim-to-shard clearance was $0.102 \mathrm{in}$, , or only 0.002 in. larger than the minimum permissible, indicating that further optimization of Flowsheet III is required to increase packing density.

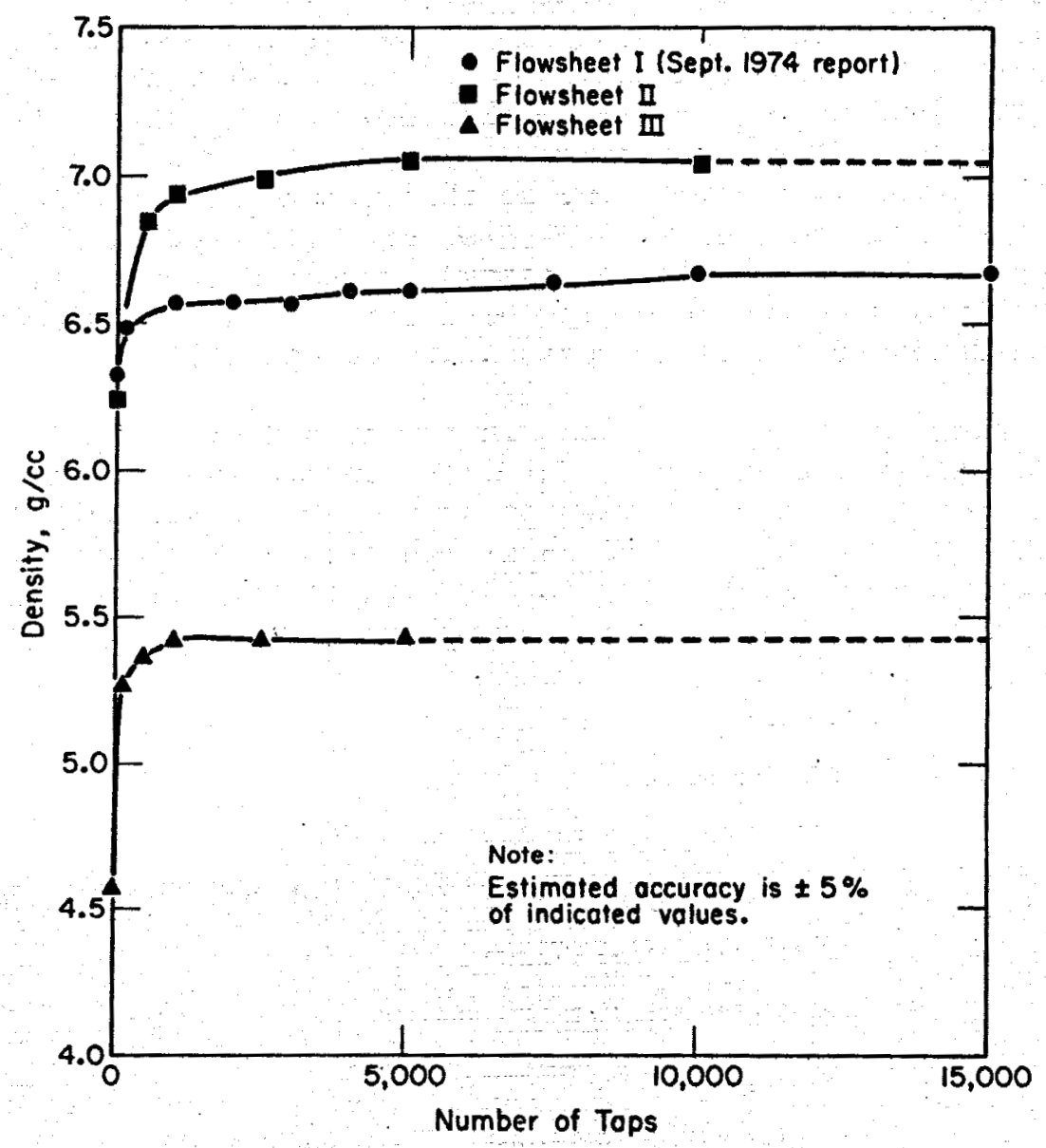

FIGURE 11. Pour and Tap Densities of Milliwatt Shards (53 to $500 \mu \mathrm{m}$ ) 


\section{Recommended Process}

The flowsheet shown in Figure 12 is the presently recommended process for fabricating Milliwatt RTG heat sources from oxalatebase shards. The bases for the specific operating parameters are described in the following paragraphs:

Calcining Temperature - The final internal density of the shards is expected to be relatively insensitive to variations in the exterior characteristics of the powder (particle size, agglomeration, powder morphology, etc.) because of the long sintering time and the high sintering temperature. This is shown by the minor differences in grain size and shard internal density (Table 10. and Figure 9). To maximize the internal density of the Milliwatt shards (and thereby maximize the loading clearance), the calcination temperature and temperature of all operations must be limited prior to presintering to the minimum practicable, i.e., the $730^{\circ} \mathrm{C}$ nominal furnace temperature currently used in HB Line. This temperature control is necessary because increased calcination temperatures and reheating of calcined oxalate-base $\mathrm{PuO}_{2}$ have been demonstrated to decrease sintered densities. ${ }^{4}$

If batch-to-batch variations in powder sinterability do have an effect, it will probably be on fines content and packing density, as both of these variables depend on the strength of the presintered pellet, which will vary with presintered density. The sensitivity of the process to these variations is not known at this time.

Fabrication

HB Line powder

${ }^{+6} \mathrm{O}_{2}$ Exchange; $8 \mathrm{hr}$ at $700^{\circ} \mathrm{C}$ in ${ }^{16} \mathrm{O}_{2}$ gas

Ball mill for $8 \mathrm{hr}$ at $100 \mathrm{rpm}$ in tantalum mills

$\downarrow$

Cold press at 58,000 psi

$+$

Presinter for $3 \mathrm{hr}$ at $1100^{\circ} \mathrm{C}$ in flowing ${ }^{16} \mathrm{O}_{2}$ gas

Crush/Size ${ }^{a}$

$+$

Sinter for $10 \mathrm{hr}$ at $1650^{\circ} \mathrm{C}$ in flowing ${ }^{16} \mathrm{O}_{2}$ gas

$+$

Wash

$\downarrow$

Dry for $1 \mathrm{hr}$ at $1000^{\circ} \mathrm{C}$ in flowing ${ }^{2} \mathrm{O}_{2}$ gas

Load

a. $25 \%$ fines to recycle.

FIGURE 12. Flowsheet for Milliwatt RTG Heat Source 
${ }^{16} \mathrm{O}_{2}$ Exchange - As with the calcination step, high oxygen exchange temperatures are avoided to assure high shard internal density. Outgassing is the next operation in normal PPO production, but is omitted in this flowsheet as outgassing is accomplished during the presintering operation, and outgassing prior to a sintering operation may compromise the final internal density of the shards.

Bal2 MiZl - Ball milling for $8 \mathrm{hr}$ in SRL-designed ball mills at $100 \mathrm{rpm}$ is sufficient to break up agglomerates and produce coldpressed pellets with a theoretical density greater than $60 \%$. Mill chambers and balls made of tantalum or T-111 material will introduce fewer objectionable impurities than the AISI 440 stainless steel alloy currently used.

Cold Press - Pellets are cold-pressed without a binder, but dispersed molybdenum disulfide is used as a die lubricant. A pressure of $58,000 \mathrm{psi}$ is sufficient to produce pellets with typical densities of $64 \%$ of theoretical. Pellets should be pressed no thicker than $1 / 4$ in., or broken into $1 / 4$ in. pieces immediately after cold-pressing, to limit temperature gradients during the presintering operation.

Presintering - The cold-pressed powder should be presintered for three hours at $1100^{\circ} \mathrm{C}$ to provide adequate strength for the breakup operation. This temperature is a compromise between packing density and fines content. Although presintering at a lower temperature than that shown in Flowsheet III will probably result in slightly increased fines content, presintering may also increase the tap density of the shards by eliminating extremely acicular shards.

Breakup - The size distribution has not been optimized, the 53 to $500 \mu \mathrm{m}$ fraction was chosen for these studies because it is the fraction currently used at Mound Laboratory. Other size ranges may improve packing density.

Sinter - A temperature of $1650^{\circ} \mathrm{C}$ for 10 hours is used for sintering shards in the production of LASL plutonium oxide - molybdenum cermet (PMC) production, and has been adopted without optimization. Shorter sintering times would result in increased throughput, but may adversely affect packing density and grain size.

Wash - The shards are rinsed using the ultrasonic rinse procedure (December 1974 report) to remove fines.

Drying - The shards are dried in flowing ${ }^{16} \mathrm{O}_{2}$ gas at $1000^{\circ} \mathrm{C}$ for one hour to remove water sorbed during the shard rinse operation. 
Loading - An electric vibrator is used to assist loading of the liner.

Program

A $70 \mathrm{~g}$ batch of Milliwatt shards will be prepared using the recommended flowsheet. Part of the shards will be retained at SRL for fines analysis, compatibility testing, and packing density measurements. The remainder will be shipped to Mound Laboratory for fines analysis. The results of the fines analyses from both laboratories will be compared. 


\section{EQUIPMENT AND FACILITIES}

\section{ALPHA MATERIALS FACILITY}

Startup of the recirculating argon system has been delayed because of leaks in the filter housings. Mating flanges are being remachined to obtain better seals between the lids and the housings. Modifications to the filter housings are expected to be completed by the first week of September.

Glove Boxes 17 and 19 have been put into service. These boxes contain a breach-lock loader/unloader fixture compatible with the HB Line shipping containers. The fixture is being used for charging $50 \mathrm{~g}$ quantities of ${ }^{238} \mathrm{PuO}_{2}$ to the glove box train and returning scrap ${ }^{238} \mathrm{PuO}_{2}$ to $\mathrm{HB}$ Line.

\section{SCRAP RECOVERY}

$568 \mathrm{~g}$ of scrap ${ }^{238} \mathrm{Pu}$ produced at SRP was charged to the dissolvers. No further scrap recovery is planned in FY-1976 because of lack of funding.

One shipment of $735.6 \mathrm{~g}$ of ${ }^{238} \mathrm{Pu}(80 \%)$ was received from LASL. The inventory of $80 \%{ }^{38} \mathrm{Pu}$ scrap totals $12,107.3 \mathrm{~g}$ and includes $10,806.3 \mathrm{~g}$ from LASL, $707.2 \mathrm{~g}$ from Mound Laboratory, and $593.8 \mathrm{~g}$ from miscellaneous sources.

The scrap inventory from the medical probe program consists of $208.4 \mathrm{~g}$ of $90 \mathrm{wt} \%{ }^{238} \mathrm{Pu}$ and $648.7 \mathrm{~g}$ of $80-86$ wt ${ }^{\%}{ }^{238} \mathrm{Pu}$. 


\section{REFERENCES}

1. R. T. DeHoff and F. N. Rhines. Quantitative Microscopy. McGraw-Hill Book Company, New York, p 50 (1968).

2. J. E. Hilliard. "Estimated Grain Size by the Intercept Method." Metal. Prog. 85(5), 99 (1964).

3. -R. L. Fullman. "Measurement of Particle Sizes in Opaque Bodies." J. Metals 5(3), 447 (1953).

4. P. E. Potter. "Studies of the Sintering Behavior of Plutonium Dioxide." J. Nucl. Mater. 15, 100 (1965).

ERRATA

July 1975 Monthly Report, DPST-75-128-7.

a. The photographs on pages 14 and 15 (Figure 3) should be interchanged,

b. The indicated magnification bars on the photographs on pages 16 and 17 (Figure 4) should be changed to read $20 \mu \mathrm{m}$ instead of $2 \mu \mathrm{m}$; those on page 19 (Figure 5) should be changed to read $220 \mu \mathrm{m}$ instead of $20 \mu \mathrm{m}$; and those on page 20 (Figure 6) should be changed to read $20 \mu \mathrm{m}$ instead of $2 \mu \mathrm{m}$.

Please make these corrections in your copies. 


\section{DISTRIBUTION}

\section{Copy No.}

1. G. A. Newby, Acting Director, Division of Space Nuclear Systems

2. B. J. Rock, Assistant Director, Development Programs, Division of Space Nuclear Systems

3. J. J. Lombardo, Deputy Assistant Director, F1ight Programs, Division of Space Nuclear Systems

4. N. R. Thielke, Heat Source Branch, Division of Space Nuclear Systems

5. T. D. Tarr, Heat Source Branch, Division of Space Nuclear Systems

6. N. Goldenberg, Assistant Director, Research and Advanced Technology Programs, Division of Space Nuclear Systems

7. V. C. Vespe, Albuquerque Operations Office

8. D. K. Nowlin, Albuquerque Operations Office

9. E. A. Walker, Dayton Area Office

10. R. D. Baker, Los Alamos Scientific Laboratory

11. R. A. Kent, Los Alamos Scientific Laboratory

12. W. T. Cave, Monsanto Research Corporation

13. D. P. Ke11y, Monsanto Research Corporation

14. C. H. Davenport, Monsanto Research Corporation

15. J. P. Shoup, Sandia Laboratory, Albuquerque

16. M. K. Parsons, Sandia Laboratory, Albuquerque

17. G. J. Jones, Sandia Laboratory, Albuquerque

18. E. W. Williams, General Electric Company, Philadelphia

19. N. B. Elsner, Gulf General Atomic, San Diego

20. W. Pardue, Battelle Memorial Institute, Columbus, Ohio

21-25. Savannah River Operations Office, ERDA

26-75. Du Pont Company, Atomic Energy Division

76-102. Technical Information Center, Oak Ridge 
I $\ldots \ldots \ldots \ldots$

\section{1}

